\title{
MIXED CONVECTION HEAT TRANSFER OF SIO2-WATER AND ALUMINA-PAO NANO-LUBRICANTS USED IN A MECHANICAL BALL BEARING
}

\author{
M. Hatami ${ }^{1,2, *}$, Farooq Hassan $\mathrm{Ali}^{3}$, Ammar I. Alsabery4,5, Songwei Hu${ }^{1}$, D. Jing ${ }^{1}$, Hameed K. Hamzah ${ }^{3}$
}

\begin{abstract}
In this study, the mixed convection heat transfer in a mechanical ball bearing filled with nano-lubricants were investigated theoretically. In our case, the bearing including eight balls revolving in counter clockwise while the inner shaft rotates in clockwise direction and the inner and outer walls of bearing were kept at constant hot and cold temperatures, respectively. Two kinds of nano-lubricants $\mathrm{SiO}_{2}$-water and Alumina- Polyalphaolefin (PAO) with different shapes of nanoparticles were considered. The governing equations including velocity, pressure, and temperature formulation were solved based on the Galerkin finite element method. The governing parameters such as nanoparticle volume fraction, Reynolds and Rayleigh numbers, etc., were discussed. It turns out that the average Nusselt number increases by increasing the nanoparticle volume fraction (averagely $15 \%$ for each 0.02 increase) and the oil-based nano-lubricant has greater Nusselt number than the water based one. More importantly, the Nono-rod Alumina was found to show much greater heat transfer performance (averagely 5\%) than the spherical alumina nanoparticles and nano-rod Alumina-PAO has the best performance and maximum Nusselt numbers for the heat transfer.
\end{abstract}

Keywords: Nanofluids, Nano-lubricant, Alumina-PAO, $\mathrm{SiO}_{2}$-water, Ball bearing, Mixed-convection

\section{INTRODUCTION}

Since Choi [1] put forward the concept of "nanofluid" for the first time in 1995, it has been playing an indispensable role in widely engaged Engineering, Physics, Chemical Engineering and Materials Science fields. Nanofluids are conventionally used for heat transfer or cooling system to replace the single-phase fluids [2]. While after many research developments in fundamental and theory, nanofluids have been extended to solar energy harvesting, medicine-drag delivery, $\mathrm{CO}_{2}$ absorption, microelectronics, lubrication of components, oil exploitation, porous media, aerospace and etc. [3-7].

As a basic property, thermal characteristics of nanofluids have been intensively studied in the past decades because of its ability to enhance thermal properties [8]. Besides, optical properties of nanofluids have also attracted much attention, especially in solar energy conversion $[9,10]$. Thus, the flow and thermal transport characteristics of the nanofluids through porous media and under the solar radiation field has become a fascinating research topic in recent years. In order to understand the conversion mechanism of the transportation as much as possible, many numerical methods have been developed. Sheikholeslami [11] put forward a new method on magneto-hydro-dynamics (MHD) Al2O3-water nanofluid transportation inside a permeable medium through Control Volume Finite Element Method (CVFEM) and Darcy model, the shape factor and Brownian motion effect were included in nanofluid modeling for the first time. Haq et al. [12] studied on a natural convection phenomenon in a porous cavity under the Lorentz forces with curved boundary domain which showed that Darcy and Hartmann number $t$ have insignificant effects on the temperature distribution. Some of the recent studies are focused on the optimization of the nanofluid heat transfer

This paper was recommended for publication in revised form by Regional Editor Younes MENNI

${ }^{1}$ International Research Center for Renewable Energy, State Key Laboratory of Multiphase Flow in Power Engineering, Xi'an

Jiaotong University, Xi'an 710049, China

${ }^{2}$ Department of Mechanical Engineering, Esfarayen University of Technology, Esfarayen, North Khorasan, Iran

${ }^{3}$ Mechanical Engineering Department, College of Engineering, University of Babylon, Babylon, Iraq

${ }^{4}$ Refrigeration \& Air-conditioning Technical Engineering Department, College of Technical Engineering, The Islamic University, Najaf, Iraq

${ }^{5}$ Centre for Modelling and Data Analysis, Faculty of Science \& Technology, University Kebangsaan Malaysia, 43600 Bangi Selangor, Malaysia

${ }^{*} E$-mail address: m.hatami2010@gmail.com

Orcid id: 0000-0001-5657-6445, 0000-0003-0082-3261, 0000-0002-2970-6600, 0000-0002-1163-5082, 0000-0001-6062-9239, 0000-

0003-0983-4776

Manuscript Received 07 February 2020, Accepted 07 March 2020 
[13-20]. In all of these studies, one or some main parameters are optimized to find the best value to have an efficient system in those applications.
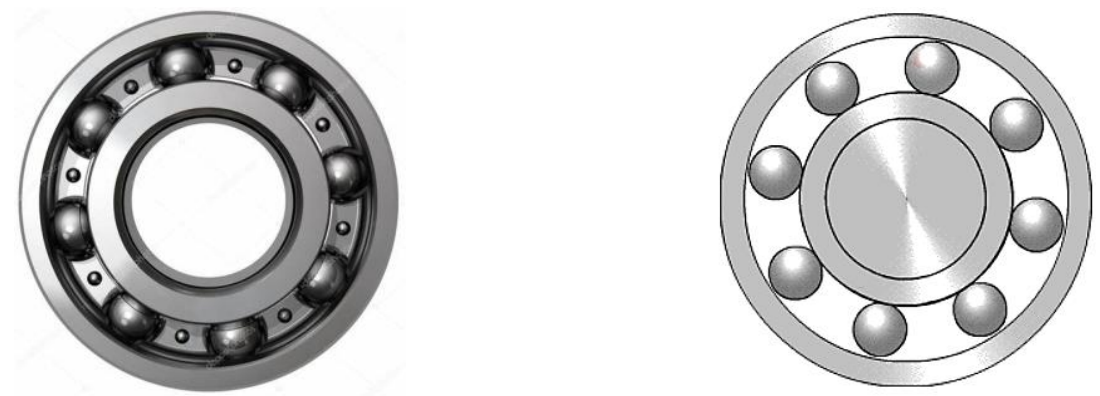

Figure 1. A mechanical ball bearing and its simple schematic

As mentioned above, a new application of nanofluids is in lubrication processes such as rolling process and ball bearings. As for nanofluids rheological property in applications, Afrand et al. [21] developed an optimal artificial neural network to predict the correlation of the nano-lubricant, which can be more accurate. Also, Asadi et al. [22] illustrated two new highly precise correlations for predicting dynamic viscosity and thermal conductivity of the nanooil. Hemmat Esfea et al. [23] investigated the rheological behavior of nanolubricants for using in the automobile cooling applications. Other applications of nano-lubricant from the energy view points and reducing costs are presented by Ahmed Ali et al. [24-25]. Furthermore, Sharif et al. [26] used $\mathrm{SiO}_{2} \mathrm{PAG}$ nanolubricant in the ventilation system of an automobile. Another application of nano-lubricant is in cooling for the rolling procedure or machining process which mostly water-based nanofluid is used [27-28]. Obviously, desired thermal distribution and enhanced heat transfer are crucial in these processes. Ali Farooq et al. [29] and Salah et al. [30] presented the governing equations of nanofluid flow (in mixed and natural convection, respectively) in an enclosure. Some researchers are performed on the $\mathrm{SiO}_{2}$-nanofluids and presented the new correlations for its thermal properties [31-35] as well as the polyalphaolefin's studies [36-41] which in the mathematical section they are reviewed in details. Recently, Hafiz Muhammad Ali et al. [42-44] developed and reported excellent outcomes on the nanofluids heat transfer, numerically and experimentally in different flow regimes. Also, they [45-48] studied the applications of hybrid nanofluids in solar energy and other heat transfer claims. One of the most important topics in this field is the magnetic effect on the nanofluid behaviors which is widely investigated by the Chamkha et al. [49-61] in different geometries. Also, they [62-78] investigated the other important parameters such as sinusoidal heating, porous media, wall thickness, entropy generation, hybrid nanofluids, flexible membrane, etc. on the nanofluids heat transfers. Furthermore, recent researchers [79-88] reviewed the nanofluids behavior in porous media, complex geometries, solar collectors, different channels and in different base fluids which is summarized efficiently for the researchers.

In this study, it is aimed to find the mixed heat transfer treatment of two kinds (water and oil based) of nanolubricant used in a ball bearing. Also, the effect of nanoparticles shape on the heat transfer will be investigated to find the best nano-lubricant from the heat transfer view point for this interesting application.

Table 1. Thermal properties of base fluid(water) and nanoparticles [35, 41]

\begin{tabular}{|c|c|c|c|c|c|}
\hline Properties & Unit & Water & PAO & $\mathbf{A l}_{2} \mathbf{O}_{3}$ & $\mathbf{S i O}_{2}$ \\
\hline Heat capacitance & $\mathrm{Jkg}^{-1} \cdot \mathrm{K}^{-1}$ & 4179 & 2303 & 765 & 765 \\
\hline Density & $\mathrm{kg} \cdot \mathrm{m}-3$ & 997.1 & 798 & 3970 & 2200 \\
\hline Thermal conductivity & $\mathrm{Wm}^{-1} \cdot \mathrm{K}^{-1}$ & 0.613 & 0.143 & 40 & 1.4 \\
\hline $\begin{array}{c}\text { Thermal expansion } \\
\text { coefficient }\end{array}$ & $\mathrm{K}^{-1}$ & $2.1 \times 10^{-4}$ & $3.5 \times 10^{-4}$ & $0.85 \times 10^{-5}$ & $0.56 \times 10^{-6}$ \\
\hline Dynamic viscosity & $\mathrm{Ns} \cdot \mathrm{m}^{-2}$ & 0.001003 & 7.34 & - & - \\
\hline
\end{tabular}


Journal of Thermal Engineering, Research Article, Vol. 7, No. 2, Special Issue 13, pp. 134-161, February, 2021

Table 2. Thermo-physical properties of $\mathrm{SiO}_{2}$-water nanofluid with $\mathrm{dp}=20 \mathrm{~nm}$ and $\varphi=0.08$

\begin{tabular}{|c|c|c|c|}
\hline Density $\left(\mathrm{kg} / \mathrm{m}^{3}\right)$ & $\begin{array}{c}\text { Dynamic viscosity } \\
\left(\mathrm{Ns} / \mathrm{m}^{2}\right)\end{array}$ & $\begin{array}{c}\text { Thermal conductivity } \\
(\mathrm{W} / \mathrm{m} . \mathrm{K})\end{array}$ & Specific heat (J/kg.K) \\
\hline 1094.344 & 0.004795 & 0.643072 & 3622.483 \\
\hline
\end{tabular}

\section{PROBLEM DESCRIPTION}

As shown in Fig. 1, a mechanical ball bearing is considered with eight heated balls. It is assumed that the space between the balls is filled with nano-lubricants such as $\mathrm{SiO}_{2}$-water and alumina-PAO nano-oil. The outer wall of bearing is kept at constant $T_{c}$, while the inner wall, due to shaft rotation, is in $T_{h}$ high temperature. As seen in Fig. 2 , detailed boundary conditions are presented while the balls temperature is $2 \mathrm{~T}_{\mathrm{h}}$ and they rotate in counter-clockwise while the inner shaft rotates in clock-wise directions. Tables 1 and 2 present the thermal properties of applied nanolubricant. It is tried to find the mixed heat transfer of these nano-lubricants, so the following non-dimensional parameters should be defined to change the dimensional governing equations [29-30]:

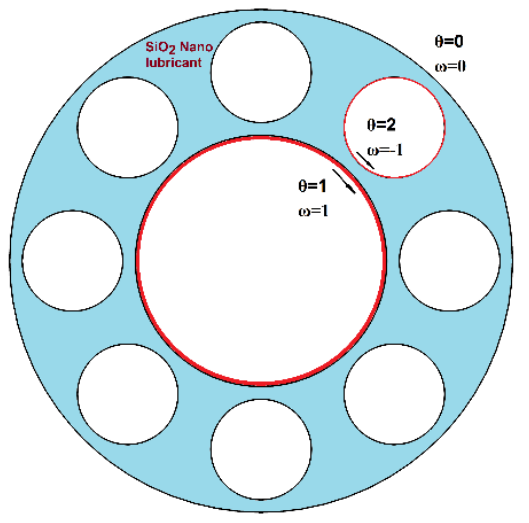

a)

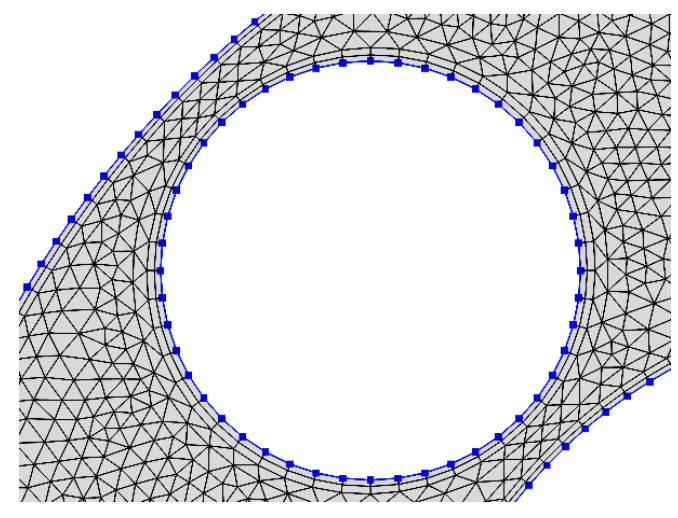

b)

Figure 2. a) Boundary conditions and, b) boundary layer mesh generation

$$
\begin{gathered}
X=\frac{x}{L}, Y=\frac{y}{L}, U=\frac{u}{u_{b}}, V=\frac{v}{u_{b}}, P=\frac{p}{\rho_{f} u_{b}^{2}} \\
\theta=\frac{T-T_{c}}{\Delta T}, R a=\frac{g \beta_{f}(\nabla T) L^{3}}{v_{f}^{2}}, \operatorname{Pr}=\frac{v_{f}}{\alpha_{f}}, \operatorname{Re}=\frac{u_{b} L}{v_{f}}
\end{gathered}
$$

The 2D mixed convection flow in the problem using conservation of mass, momentum, and energy can be written as the following dimensionless form [29-30]

$$
\begin{gathered}
\frac{\partial U}{\partial X}+\frac{\partial V}{\partial Y}=0 \\
U \frac{\partial U}{\partial X}+V \frac{\partial U}{\partial Y}=-\frac{\partial P}{\partial X}+\frac{1}{\operatorname{Re} \frac{v_{n f}}{v_{f}}\left(\frac{\partial^{2} U}{\partial X^{2}}+\frac{\partial^{2} U}{\partial Y^{2}}\right)} \\
U \frac{\partial V}{\partial X}+V \frac{\partial V}{\partial Y}=-\frac{\partial P}{\partial Y}+\frac{1}{\operatorname{Re}} \frac{v_{n f}}{v_{f}}\left(\frac{\partial^{2} V}{\partial X^{2}}+\frac{\partial^{2} V}{\partial Y^{2}}\right)+\frac{\beta_{n f}}{\beta_{f}} \frac{R a}{\operatorname{Pr}^{2} \operatorname{Re}^{2}} \theta
\end{gathered}
$$


Journal of Thermal Engineering, Research Article, Vol. 7, No. 2, Special Issue 13, pp. 134-161, February, 2021

$$
U \frac{\partial \theta}{\partial X}+V \frac{\partial \theta}{\partial Y}=\frac{1}{\operatorname{Re} \operatorname{Pr}} \frac{\alpha_{n f}}{\alpha_{f}}\left(\frac{\partial^{2} \theta}{\partial X^{2}}+\frac{\partial^{2} \theta}{\partial Y^{2}}\right)
$$

The equations of thermal properties of two different considered nano-lubricants are determined as the following sections based on the literature.

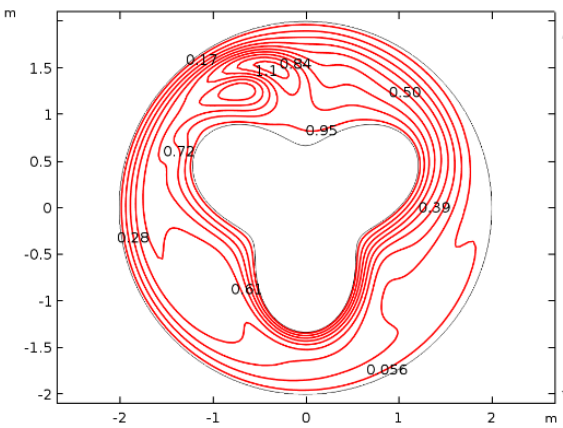

a) Farooq et al. [29]

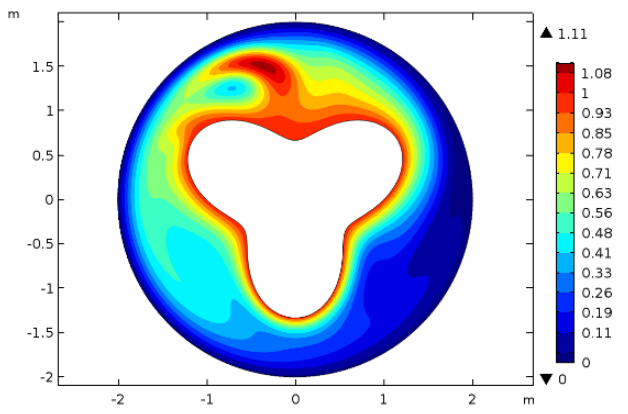

b) Current code

Figure 3. The code validation for the $\mathrm{Re}=25, \mathrm{Ra}=10000, \varphi=0.06$

Table 3. Mesh independent study for $\mathrm{SiO}_{2}$-water at $\mathrm{Re}=25, \mathrm{Ra}=10000$ and $\varphi=0.08$

\begin{tabular}{|c|c|c|c|c|}
\hline Grid size & $\begin{array}{c}\text { Number of } \\
\text { elements }\end{array}$ & $\mathbf{N u}_{\mathbf{1}}$ & $\mathbf{N u}_{\mathbf{2}}$ & CPU time (s) \\
\hline G1 & 956 & 37.102 & 6.24 & 3 \\
\hline G2 & 1019 & 43.118 & 5.54 & 3 \\
\hline G3 & 1214 & 40.722 & 4.38 & 3 \\
\hline G4 & 2064 & 38.449 & 3.68 & 2 \\
\hline G5 & 2138 & 36.008 & 4.10 & 3 \\
\hline G6 & 2756 & 41.256 & 4.46 & 3 \\
\hline G7 & 7684 & 35.769 & 3.69 & 4 \\
\hline
\end{tabular}

Table 4. Comparison of $\mathrm{Nu}_{1}$ for different nano-lubricants in various Rayleigh numbers

\begin{tabular}{|c|c|c|c|}
\hline Ra & SiO $_{2}$-water & $\begin{array}{c}\text { Spherical Alumina- } \\
\text { PAO }\end{array}$ & $\begin{array}{c}\text { Nano-rod } \\
\text { Alumina-PAO }\end{array}$ \\
\hline $\mathbf{1 0 0 0}$ & 34.463 & 333.13 & 356.58 \\
\hline $\mathbf{3 0 0 0}$ & 41.046 & 333.27 & 352.34 \\
\hline $\mathbf{5 0 0 0}$ & 42.440 & 334.18 & 363.92 \\
\hline $\mathbf{8 0 0 0}$ & 37.295 & 341.42 & 349.60 \\
\hline $\mathbf{1 0 0 0 0}$ & 41.314 & 427.06 & 344.94 \\
\hline
\end{tabular}

Table 5. Comparison of $\mathrm{Nu}_{2}$ for different nano-lubricants in various Rayleigh numbers

\begin{tabular}{|c|c|c|c|}
\hline Ra & SiO $_{2}$-water & $\begin{array}{c}\text { Spherical Alumina- } \\
\text { PAO }\end{array}$ & $\begin{array}{c}\text { Nano-rod } \\
\text { Alumina-PAO }\end{array}$ \\
\hline $\mathbf{1 0 0 0}$ & 4.4576 & 26.707 & 28.462 \\
\hline $\mathbf{3 0 0 0}$ & 4.8838 & 26.705 & 27.882 \\
\hline $\mathbf{5 0 0 0}$ & 5.6251 & 26.709 & 28.358 \\
\hline $\mathbf{8 0 0 0}$ & 3.4864 & 27.058 & 28.402 \\
\hline $\mathbf{1 0 0 0 0}$ & 5.3407 & 32.438 & 27.549 \\
\hline
\end{tabular}


Journal of Thermal Engineering, Research Article, Vol. 7, No. 2, Special Issue 13, pp. 134-161, February, 2021

\section{$\mathrm{SIO}_{2}$ Water Based Nano-Lubricant}

Since the lubricating mechanism of nanoparticles is complicated and is related to $\mathrm{SiO} 2$ suitable characteristics such as rolling friction mechanism, thin film lubrication mechanism, boundary lubrication layers and etc., it is thus used in hot rolling lubrication machinery [31-32]. Ajeel et al. [33] used the following relations for the SiO2-water thermal properties as summarized in Table $1 \& 2$.

The nanofluid density and its heat capacity can be calculated as follows [33]:

$$
\begin{gathered}
\rho_{n f}=(1-\varphi) \rho_{f}+\varphi \rho_{n p} \\
\left(\rho C_{p}\right)_{n f}=(1-\varphi)\left(\rho C_{p}\right)_{f}+\varphi\left(\rho C_{p}\right)_{n p}
\end{gathered}
$$

To compute the effective thermal conductivity, the empirical correlation has been adopted which takes into account the influence of Brownian motion as shown below [33]

$$
\begin{gathered}
k_{\text {eff }}=k_{\text {static }}+k_{\text {Brownian }} \\
k_{\text {static }}=k_{f}\left[\frac{\left(k_{n p}+2 k_{f}\right)-2 \varphi\left(k_{f}-k_{n p}\right)}{\left(k_{n p}+2 k_{f}\right)+\varphi\left(k_{f}-k_{n p}\right)}\right] \\
k_{\text {Brownian }}=5 \times 10^{4} \beta \varphi \rho_{f} C_{p f} \sqrt{\frac{K T}{2}} f(T, \varphi)
\end{gathered}
$$

where $\mathrm{K}$ is the Boltzmann constant and,

$$
\begin{aligned}
& f(T, \varphi)=\left(2.8217 \times 10^{-2} \varphi+3.917 \times 10^{-3}\right)\left(\frac{T}{T_{0}}\right) \\
& +\left(-3.0669 \times 10^{-2} \varphi-3.391123 \times 10^{-3}\right)
\end{aligned}
$$

Also, $\beta$ for the $\mathrm{SiO}_{2}$ nanoparticles is presented as [33]

$$
\beta=1.9526(100 \varphi)^{-1.4594}
$$

The effective dynamic viscosity of nanofluid is given as [34]

$$
\mu_{e f f}=\mu_{f}\left(\frac{1 \times \varphi^{-1.03}}{1-34.87\left(\frac{d_{p}}{d_{f}}\right)^{-0.3}}\right)
$$

where, equivalent diameter of based molecule is,

$$
d_{f}=\left[\frac{6 M}{N \pi \rho_{f 0}}\right] 1 / 3
$$

While Jumpholkul et al. [35] used the following relations from the literature for their $\mathrm{SiO}_{2}$-water modeling: 
Journal of Thermal Engineering, Research Article, Vol. 7, No. 2, Special Issue 13, pp. 134-161, February, 2021

$$
\begin{gathered}
\frac{\mu_{n f}}{\mu_{b f}}=\left(1+\frac{\varphi}{100}\right)^{11.3}\left(1+\frac{T_{n f}}{70}\right)^{-0.038}\left(1+\frac{d_{p}}{170}\right)^{-0.061} \\
\frac{k_{n f}}{k_{b f}}=0.8938\left(1+\frac{\varphi}{100}\right)^{1.38}\left(1+\frac{T_{n f}}{70}\right)^{0.2777}\left(1+\frac{d_{p}}{150}\right)^{-0.0336}\left(\frac{\alpha_{p}}{\alpha_{b f}}\right)^{0.01737}
\end{gathered}
$$

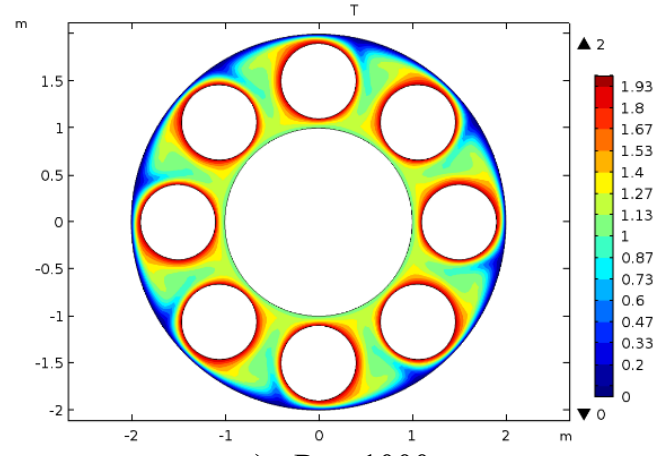

a) $\mathrm{Ra}=1000$

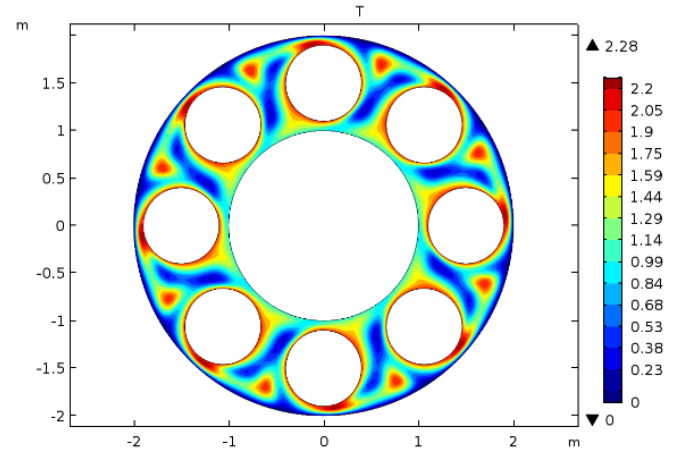

c) $\mathrm{Ra}=5000$

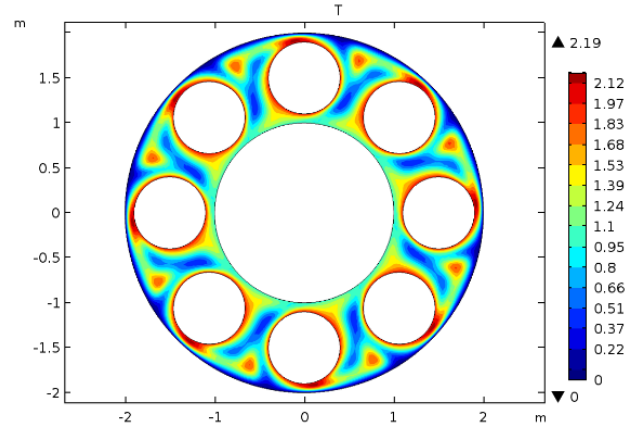

b) $\mathrm{Ra}=3000$

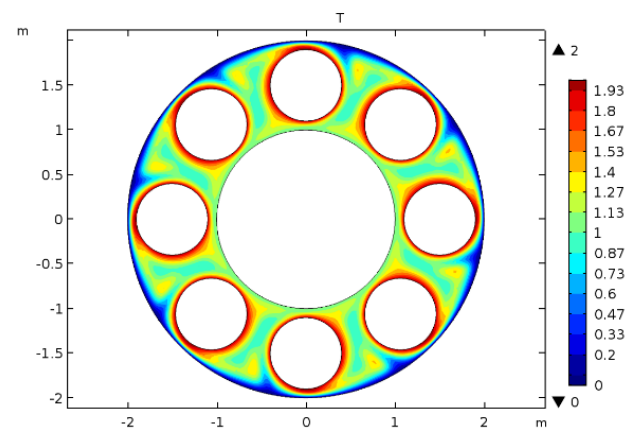

d) $\mathrm{Ra}=8000$

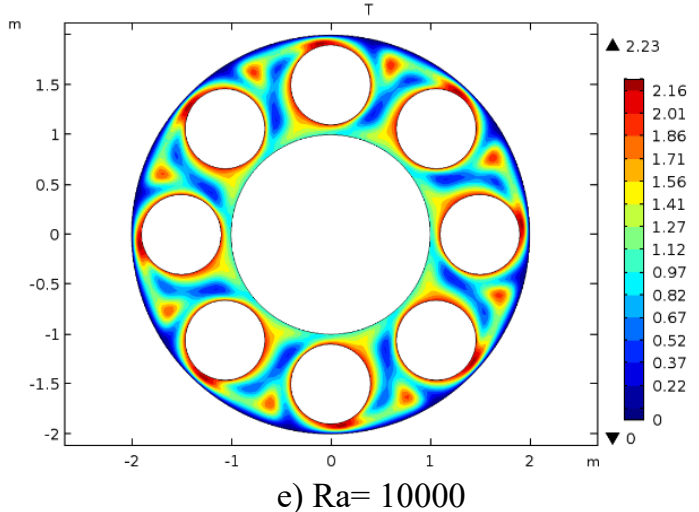

Figure 4. Temperature contours for $\mathrm{SiO}_{2}$-water nano-lubricant when $\mathrm{Re}=25, \varphi=0.08$ and different $\mathrm{Ra}$ numbers, a) 1000 , b) 3000 , c) 5000 , d) 8000 and e) 10000

\section{Alumina-PAO Based Nano-Lubricant}

Polyalphaolefin (PAO) is the most common major synthetic base oil used in industrial and automotive lubricants. PAO has more Newtonian treatment than other oil lubricants [36]. So, based on this assumption, Hajmohammadi [37] applied alumina-PAO as a nano-lubricant in a rotary system such as between two cylinders. The following correlations were used for its thermal properties [38] 
Journal of Thermal Engineering, Research Article, Vol. 7, No. 2, Special Issue 13, pp. 134-161, February, 2021

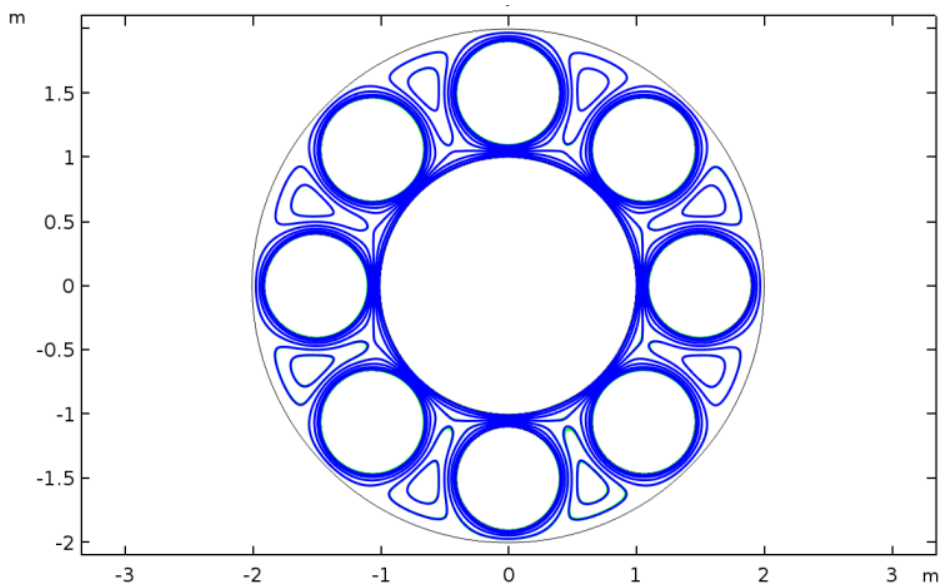

Figure 5. Streamlines for $\mathrm{SiO}_{2}$-water nano-lubricant when $\mathrm{Re}=25, \varphi=0.08$ and different $\mathrm{Ra}$ numbers

$$
\begin{gathered}
\mu_{n f}=\left[\left(1-0.3023 T+0.0051 T^{2}-0.24 T^{3}+0.1615 T^{4}\right) \times \frac{e^{\frac{2.2585}{(T+1)^{3.923}}}-0.7}{e^{2.2585}-0.7}\right] \frac{1}{(1-\varphi)^{2.5}} \\
k_{n f}=(1-0.126 T)\left[1+0.135 \times\left(\frac{k_{n}}{1-0.126 T}\right)^{0.273}(1+14.65 T)^{0.547}\left(\frac{100}{d_{p}}\right)^{0.234} \varphi^{0.467}\right]
\end{gathered}
$$

A short review of Alumina- polyalphaolefin thermal properties is performed by Yu et al. [39]

$$
\begin{array}{cc}
\rho_{n f}=(1-\varphi) \rho_{f}+\varphi \rho_{n p} & \\
\left(\rho C_{p}\right)_{n f}=(1-\varphi)\left(\rho C_{p}\right)_{f}+\varphi\left(\rho C_{p}\right)_{n p} & \\
\mu_{r}=\frac{\mu}{\mu_{f}}=1+13.67 \varphi+185.42 \varphi^{2} & \text { for Spherical nanoparticles } \\
\mu_{r}=1+27.29 \varphi+296.92 \varphi^{2} & \text { for Nano-rods nanoparticles }
\end{array}
$$

For solid-liquid mixtures, the relative thermal conductivity can be estimated by the Hamilton-Crosser model [40]

$$
k_{r}=\frac{k}{k_{f}}=\frac{k_{p}+(n-1) k_{f}-(n-1)\left(k_{f}-k_{p}\right) \varphi}{k_{p}+(n-1) k_{f}+\left(k_{f}-k_{p}\right) \varphi},
$$

where the shape factor is $n=3 / \psi$, and $\psi$ is the sphericity defined as the ratio of the surface area of a sphere (with the same volume as the given particle) to the surface area of the particle. For spherical particles, $\psi=1$. Yu et al. [39] proposed that:

$$
\begin{array}{ll}
k_{r}=1+7.6661 \varphi & \text { For spherical nanoparticles } \\
k_{r}=1+9.4539 \varphi & \text { For nano-rods nanoparticles }
\end{array}
$$

Table 2 demonstrate the PAO and alumina nanoparticles thermal properties, separately. The local Nusselt numbers along with the bearing inner and outer walls can be calculated by, 
Journal of Thermal Engineering, Research Article, Vol. 7, No. 2, Special Issue 13, pp. 134-161, February, 2021

$$
N u=\left(\frac{k_{n f}}{k_{f}}\right) \frac{\partial \theta}{\partial r}
$$

where $\mathrm{r}$ is the radial direction. The average Nusselt numbers on the bearing outer and inner walls are named as $\mathrm{Nu}_{1}$ and $\mathrm{Nu}_{2}$, respectively as:

$$
N u_{1,2}=\frac{1}{2 \pi} \int_{0}^{2 \pi} N u(\theta) d \theta
$$

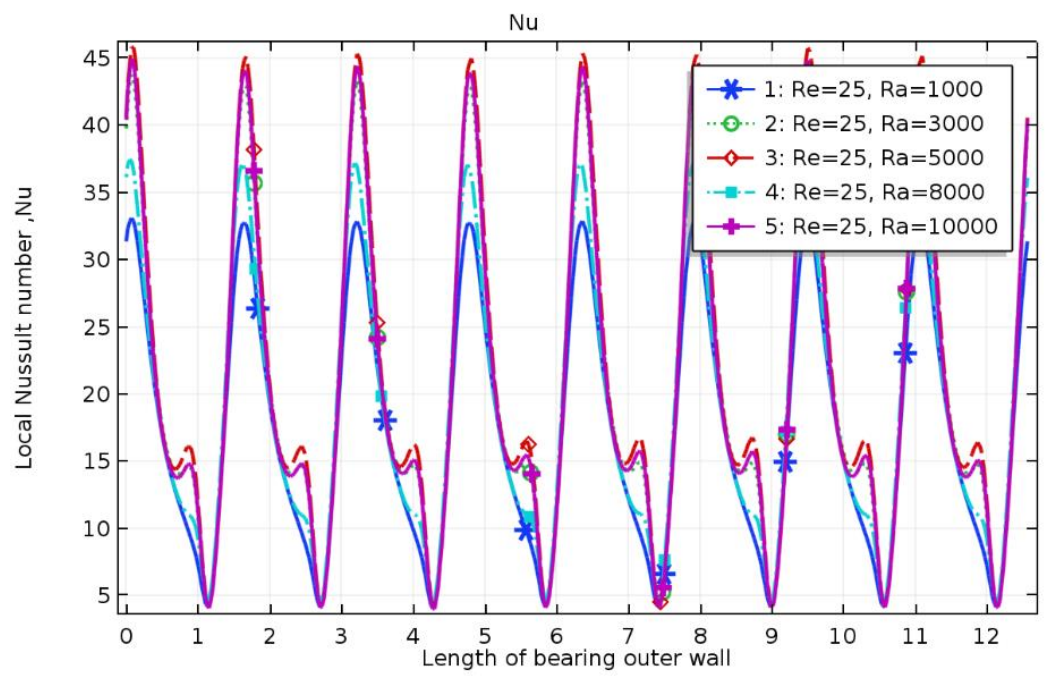

a) Outer wall

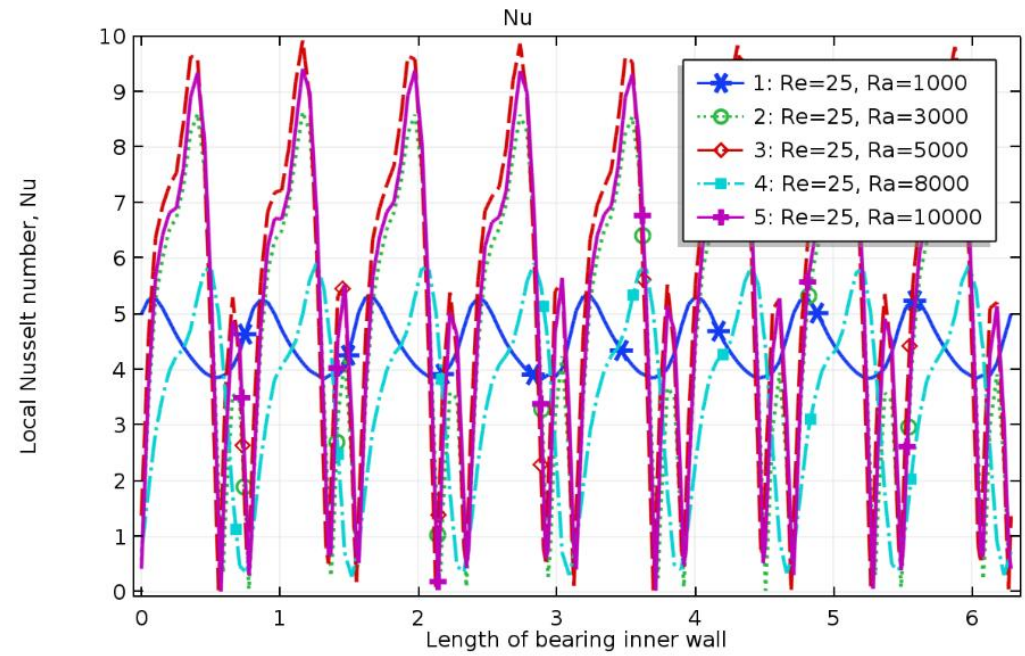

b) Inner wall

Figure 6. Local Nusselt numbers of bearings a) outer walls for $\mathrm{SiO}_{2}$-water nano-lubricant and b) inner walls for $\mathrm{SiO}_{2}$-water nano-lubricant when $\mathrm{Re}=25$ and $\varphi=0.08$ in different Rayleigh numbers 
Journal of Thermal Engineering, Research Article, Vol. 7, No. 2, Special Issue 13, pp. 134-161, February, 2021

Table 6. Comparison of $\mathrm{Nu}_{1}$ for different nano-lubricants in various Reynolds numbers

\begin{tabular}{|c|c|c|c|}
\hline $\mathbf{R e}$ & SiO$_{2}$-water & $\begin{array}{c}\text { Spherical Alumina- } \\
\text { PAO }\end{array}$ & $\begin{array}{c}\text { Nano-rod } \\
\text { Alumina-PAO }\end{array}$ \\
\hline $\mathbf{2 5}$ & 37.357 & 333.12 & 344.18 \\
\hline $\mathbf{5 0}$ & 39.751 & 331.31 & 430.62 \\
\hline $\mathbf{1 0 0}$ & 48.169 & 322.77 & 338.66 \\
\hline $\mathbf{2 0 0}$ & 61.294 & 314.23 & 325.25 \\
\hline $\mathbf{5 0 0}$ & 91.696 & 300.74 & 307.74 \\
\hline
\end{tabular}

Table 7. Comparison of $\mathrm{Nu}_{2}$ for different nano-lubricants in various Reynolds numbers

\begin{tabular}{|c|c|c|c|}
\hline $\mathbf{R e}$ & $\mathbf{S i O}_{2}$-water & $\begin{array}{c}\text { Spherical Alumina- } \\
\text { PAO }\end{array}$ & $\begin{array}{c}\text { Nano-rod } \\
\text { Alumina-PAO }\end{array}$ \\
\hline $\mathbf{2 5}$ & 3.5193 & 26.717 & 27.552 \\
\hline $\mathbf{5 0}$ & 3.2134 & 26.857 & 32.882 \\
\hline $\mathbf{1 0 0}$ & 3.3607 & 26.775 & 28.309 \\
\hline $\mathbf{2 0 0}$ & 5.5428 & 25.993 & 27.271 \\
\hline $\mathbf{5 0 0}$ & 11.208 & 27.297 & 26.904 \\
\hline
\end{tabular}

\section{METHODOLOGY OF SOLUTION}

In this study, the governing equations beside the boundary conditions are analysed numerically by Galerkin weighted residual along with finite element methods. The finite element analysis of the momentum equations (3) and (4) is showing by the following procedure:

Firstly, we employ the penalty finite element method by eliminating the pressure $(P)$ with a penalty parameter $(\lambda)$ as the following:

$$
P=-\lambda\left(\frac{\partial U}{\partial X}+\frac{\partial V}{\partial Y}\right)
$$

Leads to the following momentum equations:

$$
\begin{aligned}
& U \frac{\partial U}{\partial X}+V \frac{\partial U}{\partial Y}=\frac{\partial \lambda}{\partial X}\left(\frac{\partial U}{\partial X}+\frac{\partial V}{\partial Y}\right)+\frac{1}{R e} \frac{v_{n f}}{v_{f}}\left(\frac{\partial^{2} U}{\partial X^{2}}+\frac{\partial^{2} U}{\partial Y^{2}}\right) \\
& U \frac{\partial V}{\partial X}+V \frac{\partial V}{\partial Y}=\frac{\partial \lambda}{\partial Y}\left(\frac{\partial U}{\partial X}+\frac{\partial V}{\partial Y}\right)+\frac{1}{R e} \frac{v_{n f}}{v_{f}}\left(\frac{\partial^{2} V}{\partial X^{2}}+\frac{\partial^{2} V}{\partial Y^{2}}\right)+\frac{\beta_{n f}}{\beta_{f}} \frac{R a}{\operatorname{Pr}^{2} \operatorname{Re}^{2}} \theta
\end{aligned}
$$

Table 8. Comparison of $\mathrm{Nu}_{1}$ for different nano-lubricants in nanoparticles volume fractions

\begin{tabular}{|c|c|c|}
\hline $\boldsymbol{\varphi}$ & $\begin{array}{c}\text { Spherical Alumina- } \\
\text { PAO }\end{array}$ & $\begin{array}{c}\text { Nano-rod } \\
\text { Alumina-PAO }\end{array}$ \\
\hline $\mathbf{0 . 0 2}$ & 333.19 & 344.18 \\
\hline $\mathbf{0 . 0 4}$ & 378.57 & 405.20 \\
\hline $\mathbf{0 . 0 6}$ & 409.67 & 537.79 \\
\hline $\mathbf{0 . 0 8}$ & 435.03 & 483.34 \\
\hline
\end{tabular}


Journal of Thermal Engineering, Research Article, Vol. 7, No. 2, Special Issue 13, pp. 134-161, February, 2021

Table 9. Comparison of $\mathrm{Nu}_{2}$ for different nano-lubricants in nanoparticles volume fractions

\begin{tabular}{|c|c|c|}
\hline $\boldsymbol{\varphi}$ & $\begin{array}{c}\text { Spherical } \\
\text { Alumina-PAO }\end{array}$ & $\begin{array}{c}\text { Nano-rod } \\
\text { Alumina-PAO }\end{array}$ \\
\hline $\mathbf{0 . 0 2}$ & 26.701 & 27.552 \\
\hline $\mathbf{0 . 0 4}$ & 30.258 & 32.602 \\
\hline $\mathbf{0 . 0 6}$ & 36.657 & 43.307 \\
\hline $\mathbf{0 . 0 8}$ & 47.417 & 44.356 \\
\hline
\end{tabular}

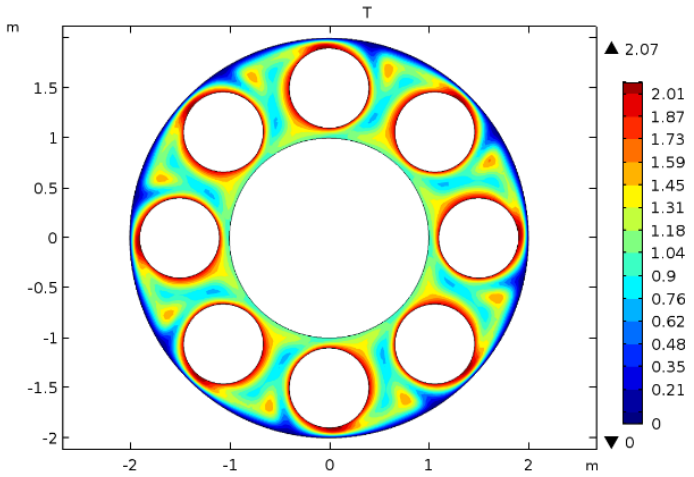

a) $\operatorname{Re}=25$

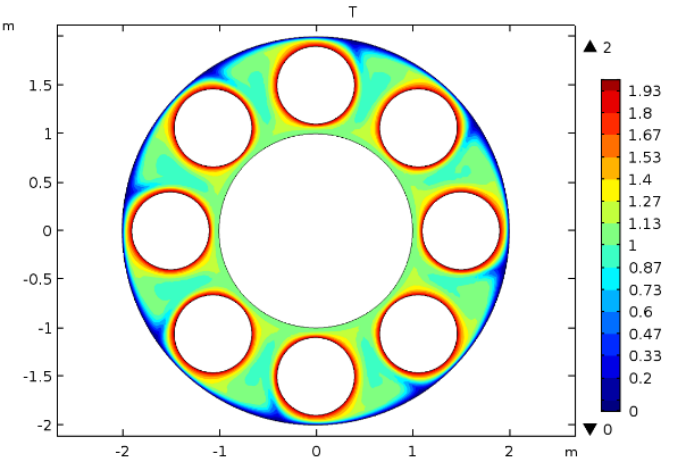

c) $\operatorname{Re}=100$

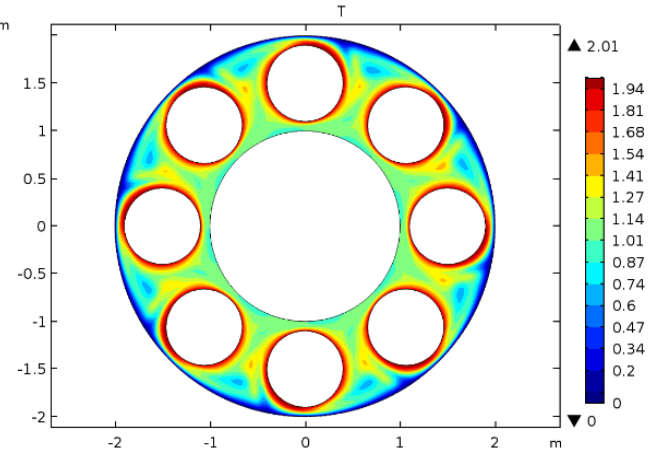

b) $\mathrm{Re}=50$

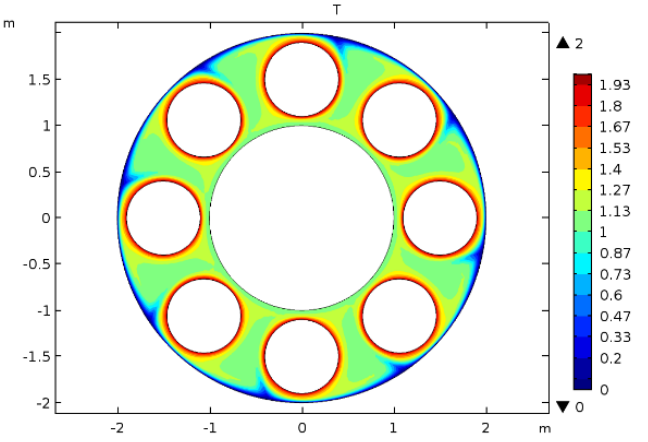

d) $\operatorname{Re}=200$

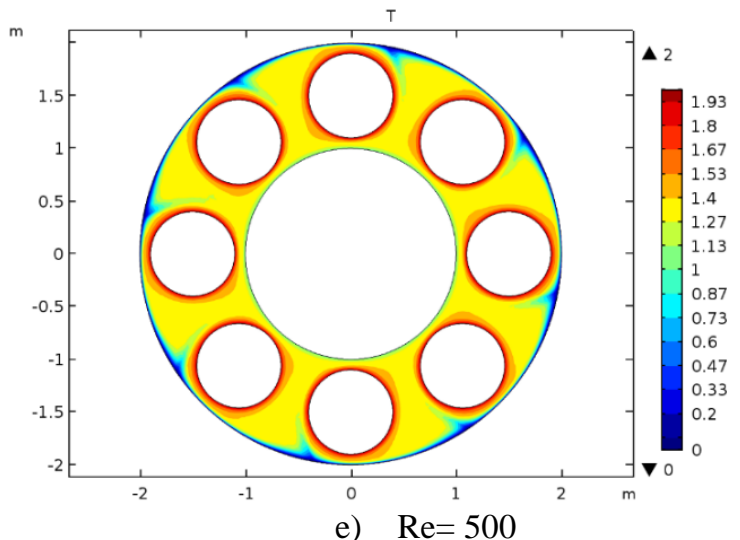

Figure 7. Temperature contours for $\mathrm{SiO}_{2}$-water nano-lubricant when $\mathrm{Ra}=10000, \varphi=0.08$ and different $\mathrm{Re}$ numbers, a) 25 , b) 50 , c) 100 , d) 200 and e) 500 
Journal of Thermal Engineering, Research Article, Vol. 7, No. 2, Special Issue 13, pp. 134-161, February, 2021

The weak (or weighted-integral) formulation of the momentum equations by multiplying the equation by an internal domain $(\Phi)$ and integrating it over the computational domain which is discretised into small triangular elements as shown in Fig. 2. The following weak formulations are obtained:

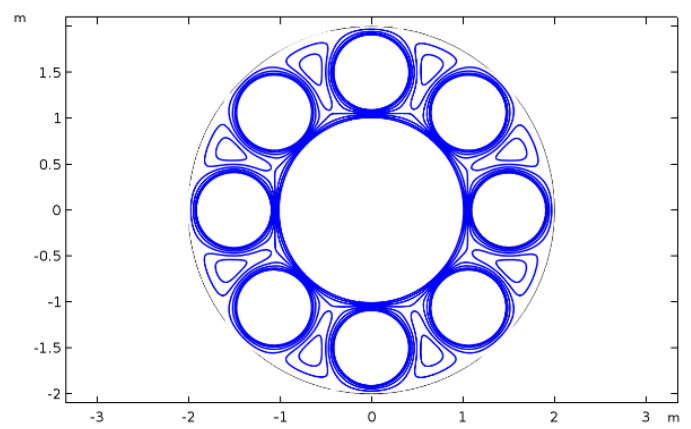

a) $\operatorname{Re}=50$

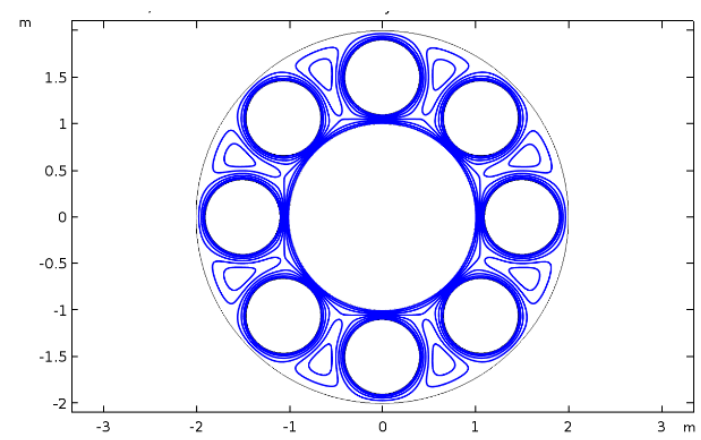

c) $\operatorname{Re}=200$

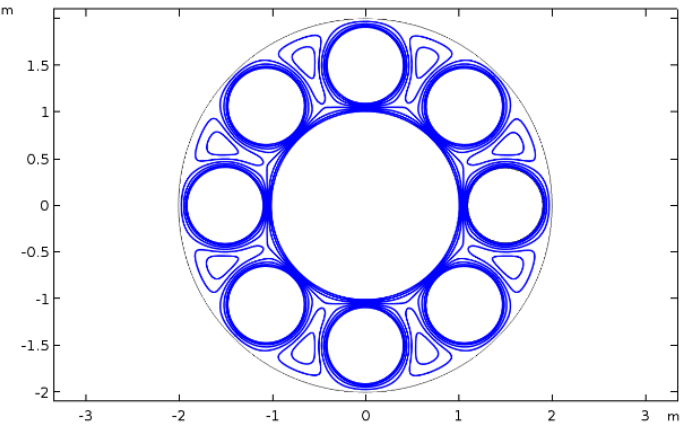

b) $\operatorname{Re}=100$

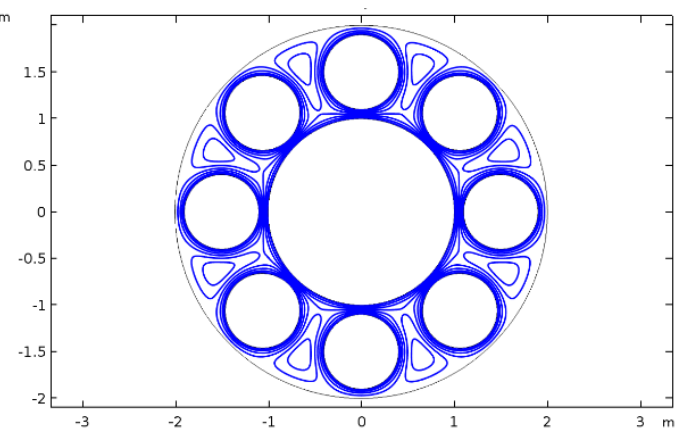

d) $\quad \mathrm{Re}=500$

Figure. 8 Streamlines for $\mathrm{SiO}_{2}$-water nano-lubricant when $\mathrm{Ra}=10000, \varphi=0.08$ and different $\mathrm{Re}$ numbers, a) 50, b) 100 , c) 200 and d) 500

$$
\begin{gathered}
\int_{\Omega}\left(\Phi_{i} U^{k} \frac{\partial U^{k}}{\partial X}+\Phi_{i} V^{k} \frac{\partial U^{k}}{\partial Y}\right) \mathrm{dXd} \mathrm{Y}=\lambda \int_{\Omega} \frac{\partial \Phi_{i}}{\partial X}\left(\frac{\partial U^{k}}{\partial X}+\frac{\partial V^{k}}{\partial Y}\right) \mathrm{dXdY} \\
+\frac{1}{\operatorname{Re}} \frac{v_{n f}}{v_{f}} \int_{\Omega} \Phi_{i}\left(\frac{\partial^{2} U^{k}}{\partial X^{2}}+\frac{\partial^{2} U^{k}}{\partial Y^{2}}\right) \mathrm{dXdY} \\
\int_{\Omega}\left(\Phi_{i} V^{k} \frac{\partial V^{k}}{\partial X}+\Phi_{i} V^{k} \frac{\partial V^{k}}{\partial Y}\right) \mathrm{dXdY}=\lambda \int_{\Omega} \frac{\partial \Phi_{i}}{\partial Y}\left(\frac{\partial U^{k}}{\partial X}+\frac{\partial V^{k}}{\partial Y}\right) \mathrm{dXdY} \\
+\frac{1}{\operatorname{Re}} \frac{v_{n f}}{v_{f}} \int_{\Omega} \Phi_{i}\left(\frac{\partial^{2} V^{k}}{\partial X^{2}}+\frac{\partial^{2} V^{k}}{\partial Y^{2}}\right) \mathrm{dXdY}+\frac{\beta_{n f}}{\beta_{f}} \frac{\operatorname{Ra}}{\operatorname{Pr}^{2} \int_{\Omega} \Phi_{i} \theta^{k} \mathrm{dXdY} .}
\end{gathered}
$$

Selection of the interpolation functions for providing an approximation for the velocity distribution and temperature distribution as:

$$
U \approx \sum_{j=1}^{m} U_{j} \Phi_{j}(X, Y), \quad V \approx \sum_{j=1}^{m} V_{j} \Phi_{j}(X, Y), \quad \theta \approx \sum_{j=1}^{m} \theta_{j} \Phi_{j}(X, Y)
$$

The nonlinear residual equations for the momentum equations that obtained from the Galerkin weighted residual finiteelement method are: 
Journal of Thermal Engineering, Research Article, Vol. 7, No. 2, Special Issue 13, pp. 134-161, February, 2021

$$
\begin{aligned}
R(1)_{i}= & \sum_{j=1}^{m} U_{j} \int_{\Omega}\left[\left(\sum_{j=1}^{m} U_{j} \Phi_{j}\right) \frac{\partial \Phi_{j}}{\partial X}+\left(\sum_{j=1}^{m} V_{j} \Phi_{j}\right) \frac{\partial \Phi_{j}}{\partial Y}\right] \Phi_{i} \mathrm{dXdY} \\
& +\lambda\left[\sum_{j=1}^{m} U_{j} \int_{\Omega} \frac{\partial \Phi_{i}}{\partial X} \frac{\partial \Phi_{j}}{\partial X} \mathrm{dXdY}+\sum_{j=1}^{m} V_{j} \int_{\Omega} \frac{\partial \Phi_{i}}{\partial X} \frac{\partial \Phi_{j}}{\partial Y} \mathrm{dXdY}\right] \\
& +\frac{1}{R e} \frac{v_{n f}}{v_{f}} \sum_{j=1}^{m} U_{j} \int_{\Omega}\left[\frac{\partial \Phi_{i}}{\partial X} \frac{\partial \Phi_{j}}{\partial X}+\frac{\partial \Phi_{i}}{\partial Y} \frac{\partial \Phi_{j}}{\partial Y}\right] \mathrm{dXdY}, \\
R(2)_{i}= & \sum_{j=1}^{m} V_{j} \int_{\Omega}\left[\left(\sum_{j=1}^{m} U_{j} \Phi_{j}\right) \frac{\partial \Phi_{j}}{\partial X}+\left(\sum_{j=1}^{m} V_{j} \Phi_{j}\right) \frac{\partial \Phi_{j}}{\partial Y}\right] \Phi_{i} \mathrm{dXdY} \\
+ & \lambda\left[\sum_{j=1}^{m} U_{j} \int_{\Omega} \frac{\partial \Phi_{i}}{\partial Y} \frac{\partial \Phi_{j}}{\partial X} \mathrm{dXdY}+\sum_{j=1}^{m} V_{j} \int_{\Omega} \frac{\partial \Phi_{i}}{\partial Y} \frac{\partial \Phi_{j}}{\partial Y} \mathrm{dXdY}\right] \\
+\frac{1}{R e} & \frac{v_{n f}}{v_{f}} \sum_{j=1}^{m} V_{j} \int_{\Omega}\left[\frac{\partial \Phi_{i}}{\partial X} \frac{\partial \Phi_{j}}{\partial X}+\frac{\partial \Phi_{i}}{\partial Y} \frac{\partial \Phi_{j}}{\partial Y}\right] \mathrm{dXdY}+\frac{\beta_{n f}}{\beta_{f}} \frac{R a}{\operatorname{Pr} \operatorname{Re}^{2}} \int_{\Omega}\left(\sum_{j=1}^{m} \theta_{j} \Phi_{j}\right) \Phi_{i} \mathrm{dXdY},
\end{aligned}
$$

where the superscript $k$ is the approximate index, subscripts $i, j$ and $m$ are the residual number, node number and iteration number, respectively. To simplify the nonlinear terms in the momentum equations, a Newton-Raphson iteration algorithm was used. The iteration of the present study is assumed to be convergence solution when the corresponding error of each variable is equal or less than $10^{-5}$.

\section{RESULTS AND DISCUSSION VALIDATION STUDY}

To validate the current FEM code based on Galerkin weighted residual method, the initial code results is compared to Farooq et al. [29] outcomes as depicted in Fig. 3. As seen the temperature contours values and shapes are exactely the same and the maximum value of temperature in both figures are approximately 1.1 which confirms the accuracy and validity of current code.

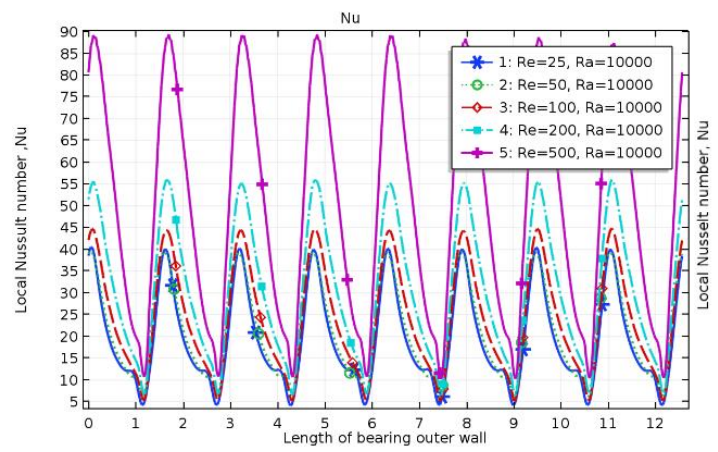

a) outer wall

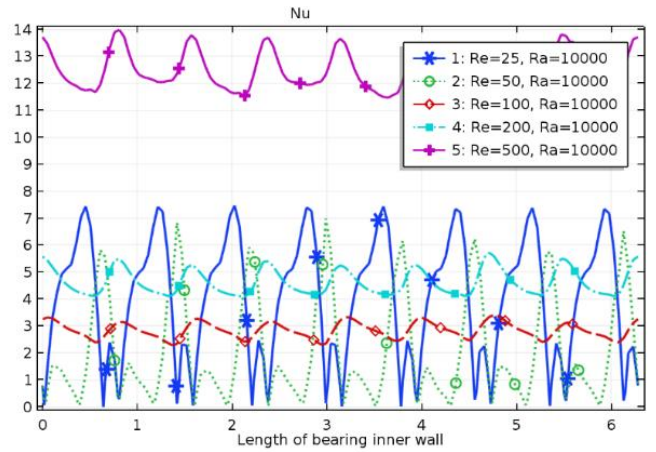

b) inner wall

Figure 9. Local Nusselt numbers of bearings a) outer walls for $\mathrm{SiO}_{2}$-water nano-lubricant and b) inner walls for $\mathrm{SiO}_{2}$-water nano-lubricant when $\mathrm{Ra}=10000$ and $\varphi=0.08$ in different Reynolds numbers

\section{Mesh Independency}

As depicted in Fig. 2, mesh generation on the geometry is made using triangles while over the three boundaries (outer, inner and balls walls) boundary mesh layer is applied for better accuracy which are in quad shapes. In this section, eight grid sensitivity tests were conducted to determine the sufficiency of the mesh scheme and ensure that the 
results are grid independent as depicted in Table 3 for $\mathrm{SiO} 2$-water at $\mathrm{Re}=25, \mathrm{Ra}=10000$ and $\varphi=0.08$. As seen for both $\mathrm{Nu} 1$ and $\mathrm{Nu} 2$ results, the $\mathrm{G} 7$ grid is the most suitable grid size from both accuracy and time computation study.

\section{$\mathrm{SIO}_{2}$-Water Nano-Lubricant}

As mentioned in introduction section, water-based nano-lubricant is more often used for the rolling machinery for cooling and lubricating purposes. In this section, it is tried to see its performance in ball bearing lubricant application and compare the results with the oil-based nano-lubrcant which is presented in next section. Figs. 4-9 are depicted for the $\mathrm{SiO}_{2}$-water nano-lubricant with $\varphi=0.08$ to show the effect of Reynolds and Rayleigh numbers on the results. Fig. 4 and Fig. 5 demonstrate the effect of Ra on the temperature and stream lines contours, respectively. As seen for the $\mathrm{Ra}=8000$ case, due to natural convection effect, the temperatures value between the balls is greater than the other cases, while for the streamline, due to low velocity of $\mathrm{Re}=25$, there is not a significant change between the graphs and just one case is presented as sample case. The effects of the Ra numbers on the local $\mathrm{Nu}_{1}$ and $\mathrm{Nu}_{2}$ (for outer and inner walls, respectively) are depicted in Fig. 6 . For both walls, $\mathrm{Ra}=10000$ has the maximum values of Nusselt numbers and also have the maximum range of variations, while the $\mathrm{Ra}=1000$ has the minimum values of variations which is approximately 1 on the inner wall length. Figs. $7 \& 8$ show the effect of Reynolds numbers on the temperature and streamline contours, respectively when $\mathrm{Ra}=10000, \varphi=0.08$. As seen for the $\mathrm{Re}=500$, the maximum temperatures between the balls occurs. Therefore, this case is considered to have more heat transfer performance than the others. This fact is depicted in Fig. 9 for the local Nusselt numbers. The maximum local Nusselt numbers (for both walls) occurs for the $\mathrm{Re}=500$ and maximum variation for the outer wall occurs for this case while for the inner case maximum variation of Nusselt numbers happens for the $\mathrm{Re}=25$. These variations have a significant effect on the average Nusselt numbers which will be fully discussed in section 4.5 .

\section{Alumina-PAO Nano-Lubricant}

In this section the effect of alumina-PAO nano-lubricant on the mixed heat transfer mechanism is investigated through Figs. 10-19 for two kinds of nanoparticle shapes, i.e., spherical and nano-rods. Figs. 10-15 show the effect of spherical alumina nanoparticles on the results. Fig. 10 presents the Ra effects on the temperature and streamline contours. By increasing the Ra, the temperature distribution in the domain is much greater due to better heat transfer through the natural convection mechanism. However, in the stream lines there is not a significant difference due to high viscosity of PAO and low Reynolds numbers $(\mathrm{Re}=25)$. Based on this definitions Fig. 11 confirms that $\mathrm{Ra}=10000$ has the maximum values of local Nusselt numbers for the both walls under study. Fig. 12 shows that by increasing the Re number (against the Ra increasing) the streamline contours varies significantly and vortexes between the balls deformed from symmetry (for $\mathrm{Re}=25$ ) to asymmetry (for $\mathrm{Re}=500$ ) due to nano-lubricant flow in higher Re numbers. This effect of Re numbers on the local Nusselt numbers are depicted via Fig. 13 which confirms that $R e=500$ has the maximum values and variations of Nusselt numbers. To see the effect of spherical nanoparticles volume fractions on the heat transfer mechanism, Figs. $14 \& 15$ are depicted for $\mathrm{Ra}=10000, \mathrm{Re}=25$. It is completely clear that increasing the nanoparticles volume fraction make an enhancement in the heat transfer and improvements in local Nusselt numbers, consequently. 
Journal of Thermal Engineering, Research Article, Vol. 7, No. 2, Special Issue 13, pp. 134-161, February, 2021
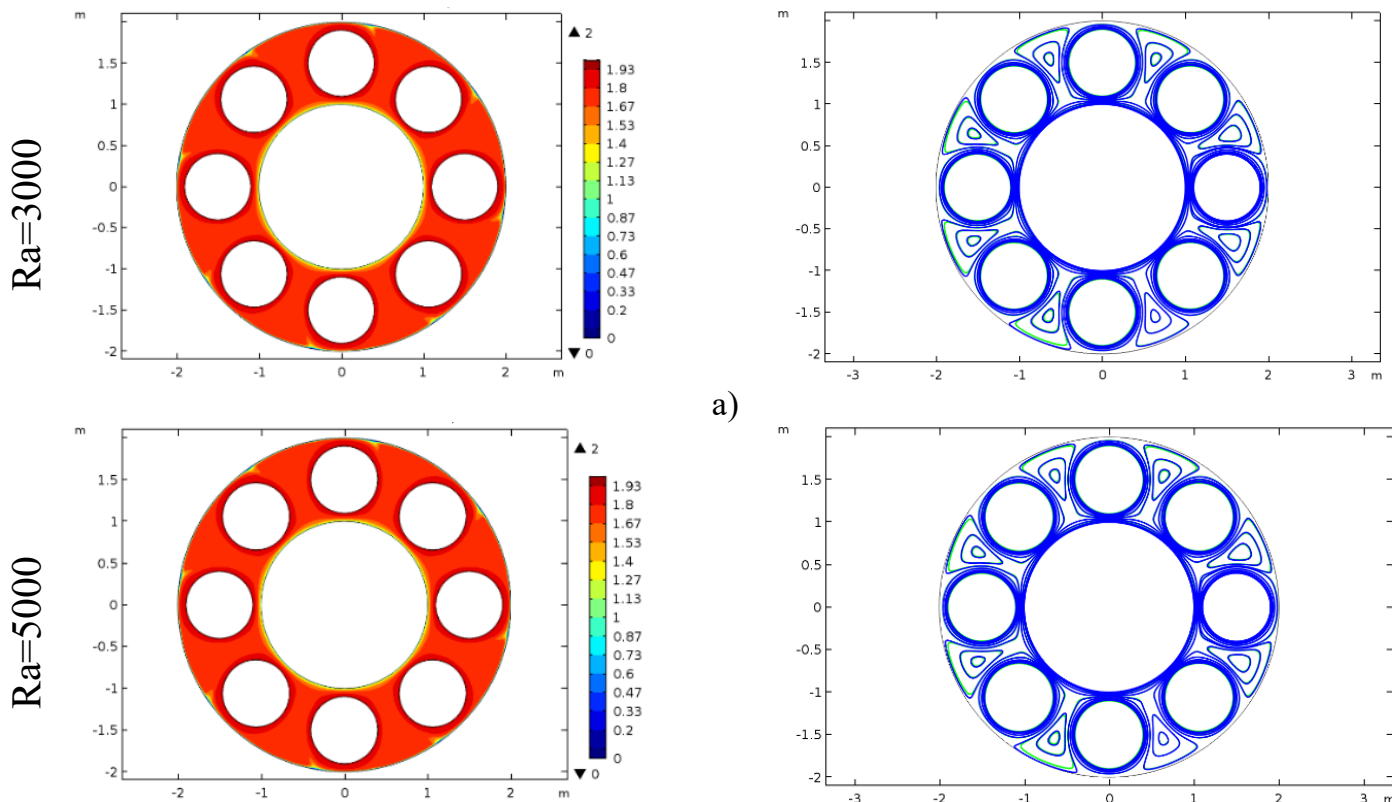

a)
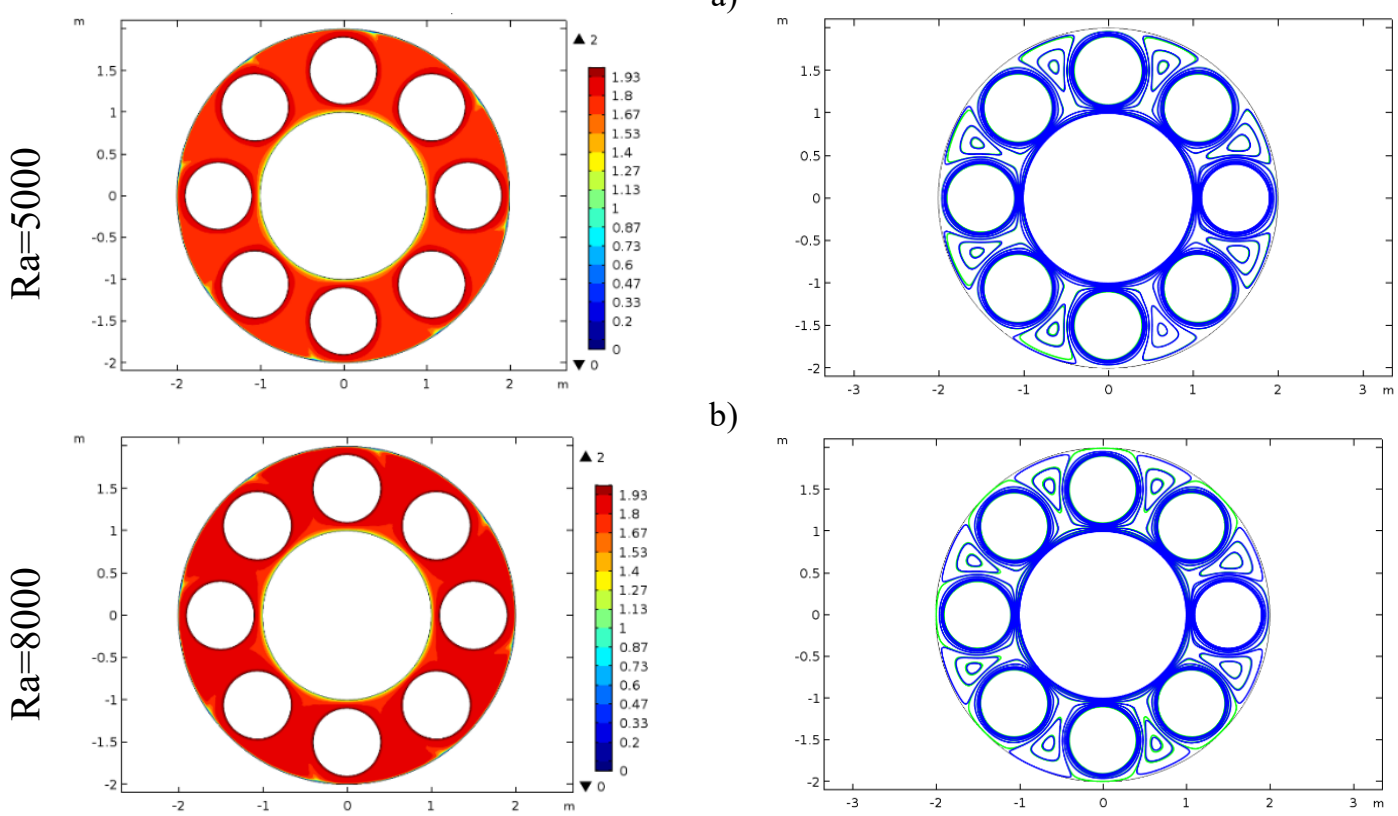

b)
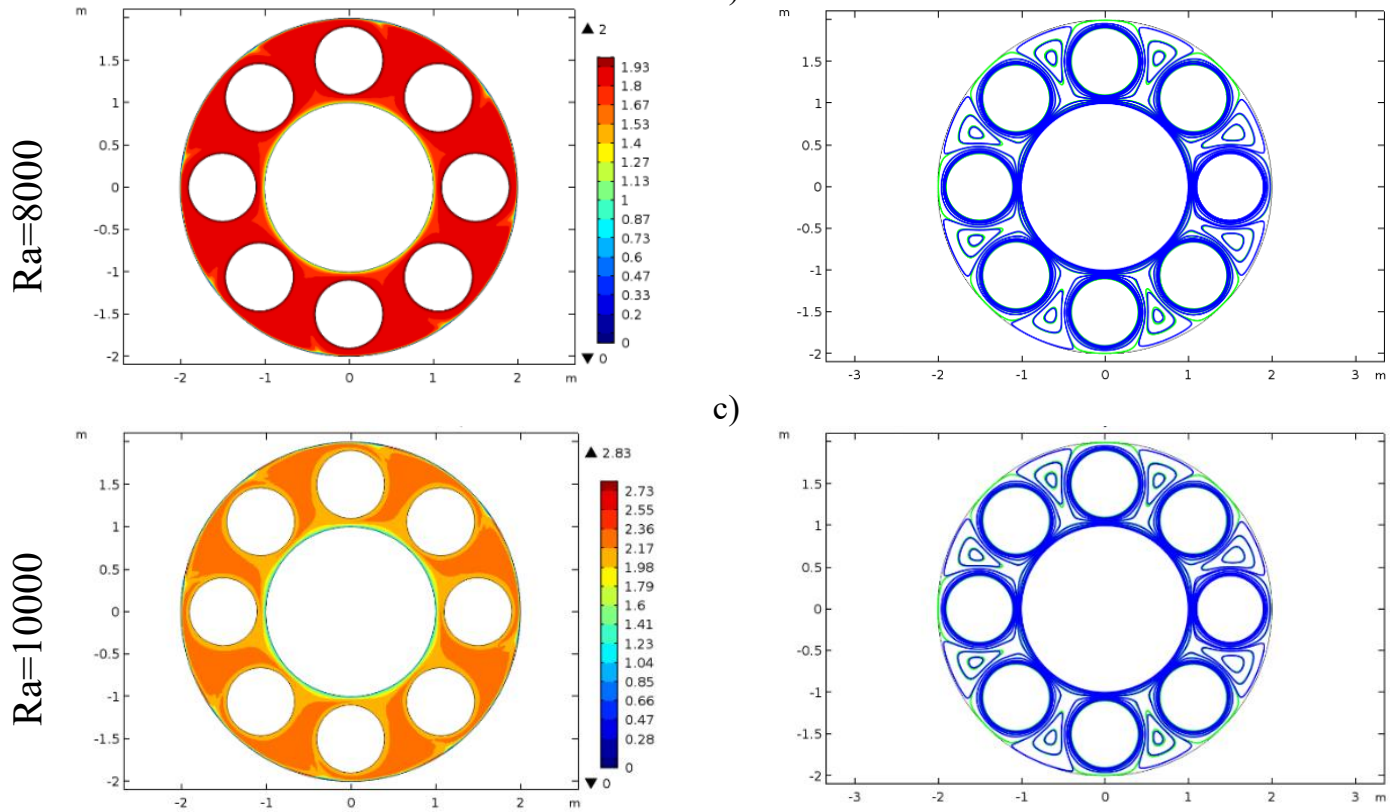

c)

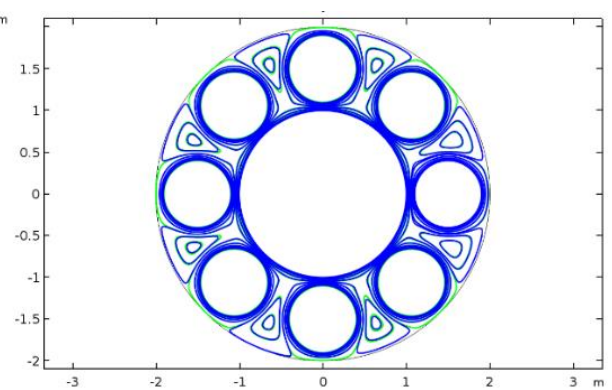

d)

Figure 10. Temperature contours and streamlines for spherical Alumina-PAO nano-lubricant for $\varphi=0.02$, $\mathrm{Re}=25$ and different Ra numbers, a) 3000, b) 5000, c) 8000 and d) 10000 
Journal of Thermal Engineering, Research Article, Vol. 7, No. 2, Special Issue 13, pp. 134-161, February, 2021

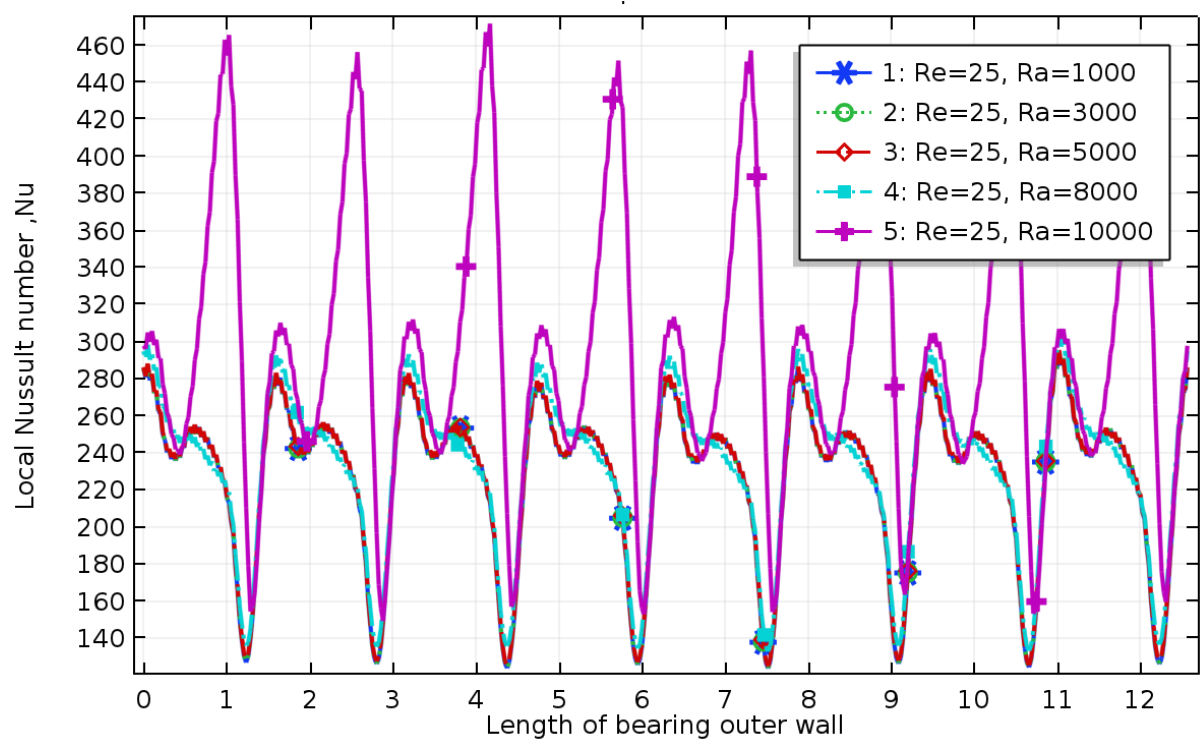

a)

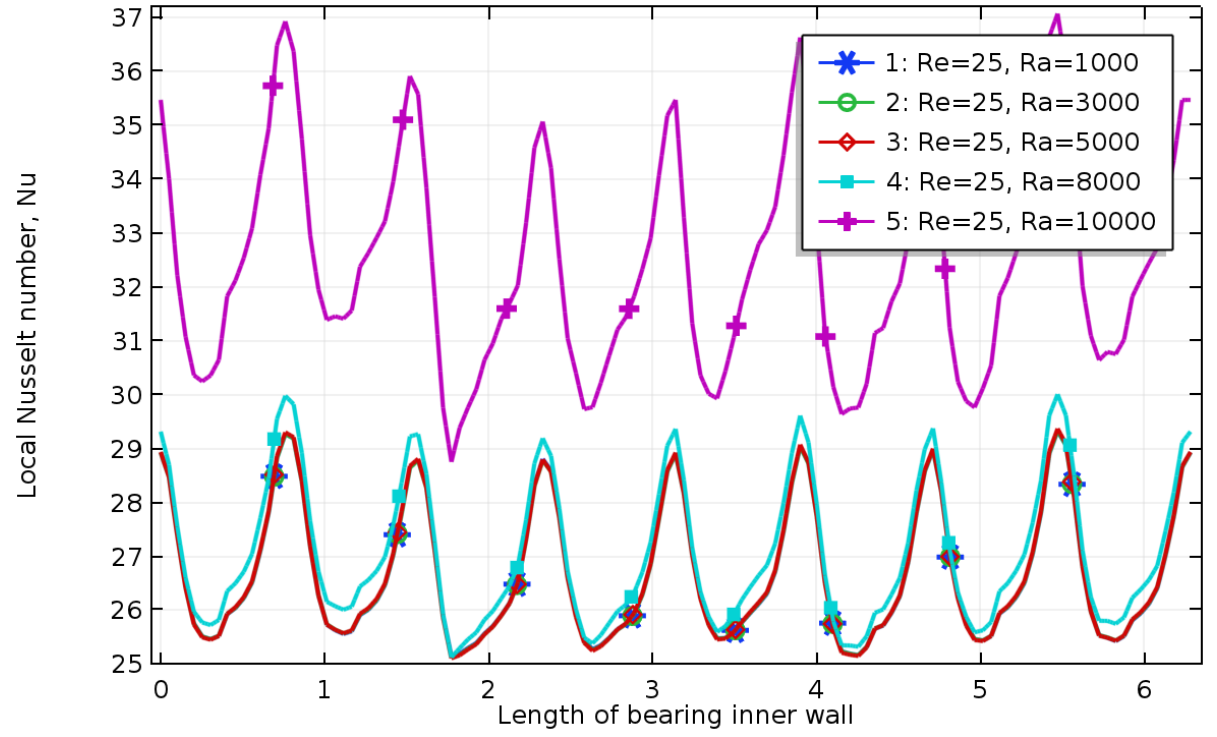

b)

Figure 11. a) Local Nusselt numbers of bearings outer walls for spherical Alumina-PAO nanolubricant and b) Local Nusselt numbers of bearings inner walls for spherical Alumina-PAO nanolubricant when $\mathrm{Re}=25$ and $\varphi=0.02$ and different Rayleigh numbers

Figures 16-19 are presented for the nano-rods alumina-PAO nano-lubricant results. In this case, as seen in Fig. 16, $\mathrm{Ra}=1000$ and 3000 has greater maximum values of local Nusselt number of outer wall while for the inner wall maximum values occurs for the $\mathrm{Ra}=5000$. When $\mathrm{Ra}$ becomes $=10000$, it has the minimum peak values in Nusselt numbers. The results could be attributed to the difference between viscosity and thermal conductivity of these two nanoparticle shapes as presented in section 2.2. Based on defined equations alumina nano-rods has greater viscosity and thermal conductivity than spherical nanoparticles. Figs. 17 and 18 shows the effect of Re number on the outcomes $\mathrm{Re}=50$ has the maximum values of Nusselt numbers as seen in the graphs. Finally, the effect of nanoparticles volume fraction on the local Nusselt numbers is depicted in Fig. 19. Increasing this parameter in nano-rods makes an improvement in Nusselt numbers as well as the spherical nanoparticles treatments. 


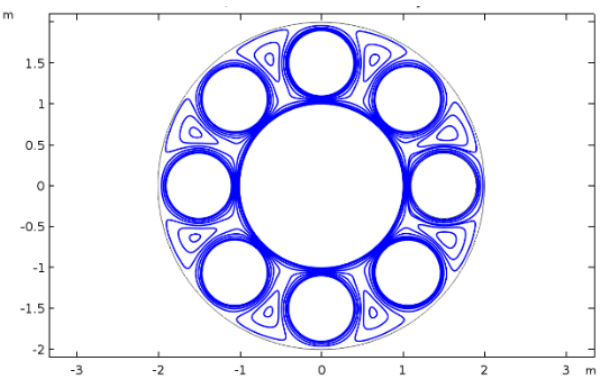

a) $\mathrm{Re}=50$

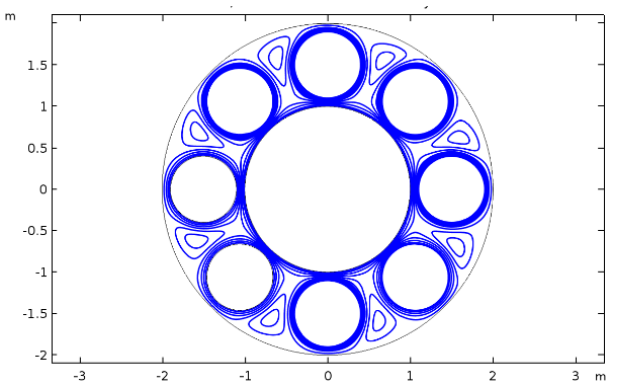

c) $\operatorname{Re}=200$

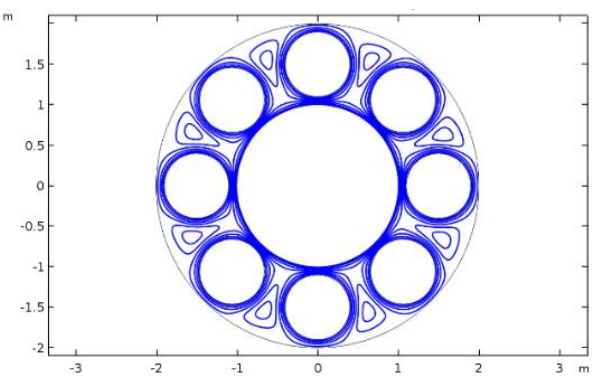

b) $\operatorname{Re}=100$

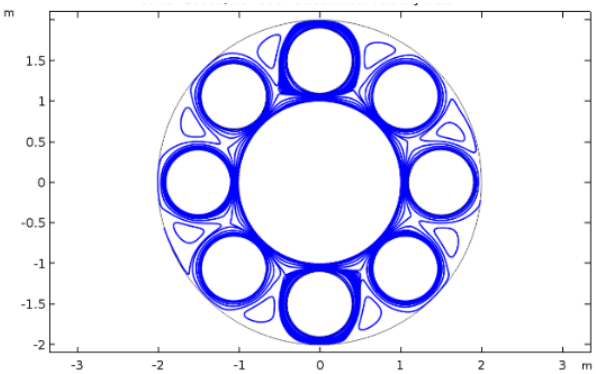

d) $\mathrm{Re}=500$

Figure 12. Streamlines for spherical Alumina-PAO nano-lubricant when $\mathrm{Ra}=10000, \varphi=0.02$ and different Re numbers, a) 50, b)100, c) 200, d) 500

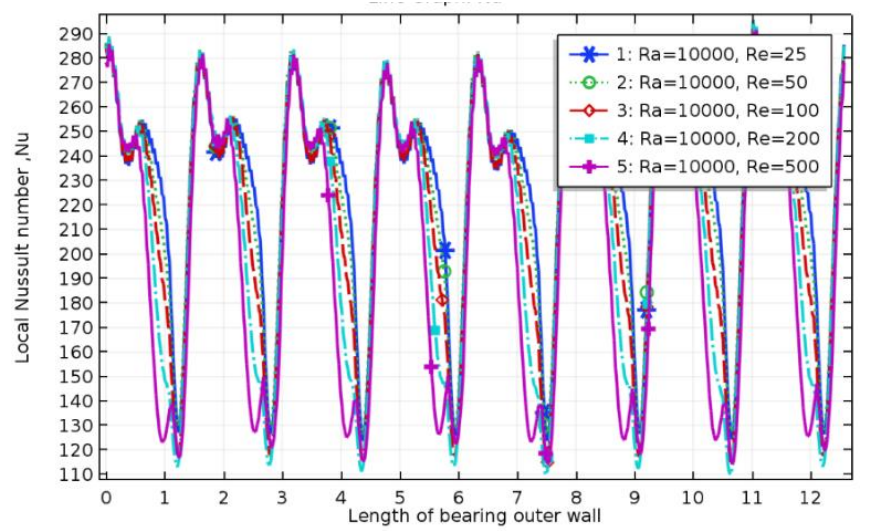

a)

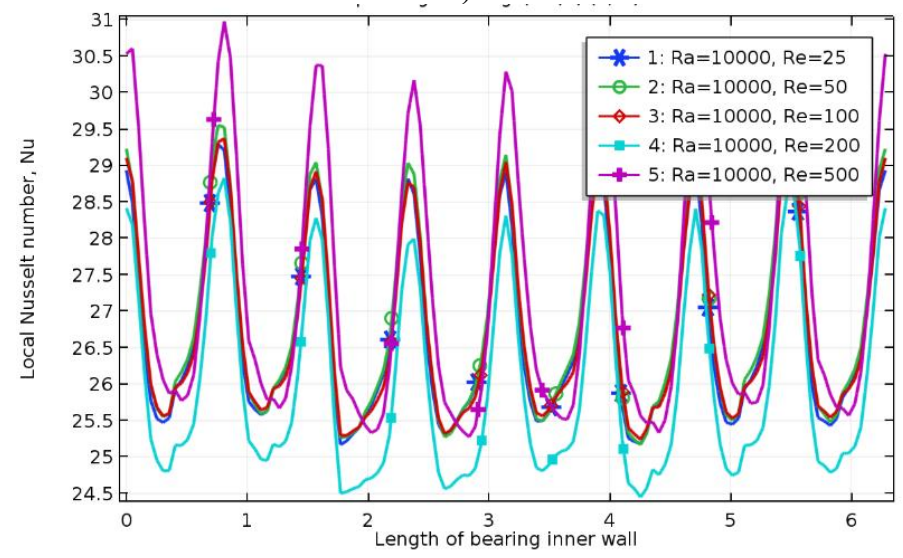

b)

Figure 13. a) Local Nusselt numbers of bearings outer and b) inner walls for spherical AluminaPAO nano-lubricant when $\mathrm{Ra}=10000$ and $\varphi=0.02$ and different Reynolds numbers 
Journal of Thermal Engineering, Research Article, Vol. 7, No. 2, Special Issue 13, pp. 134-161, February, 2021
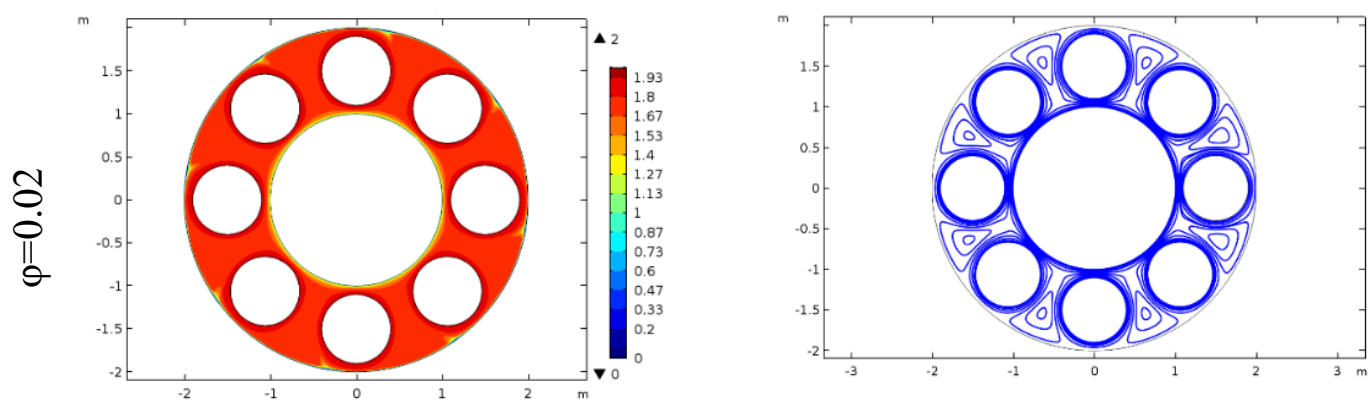

a)
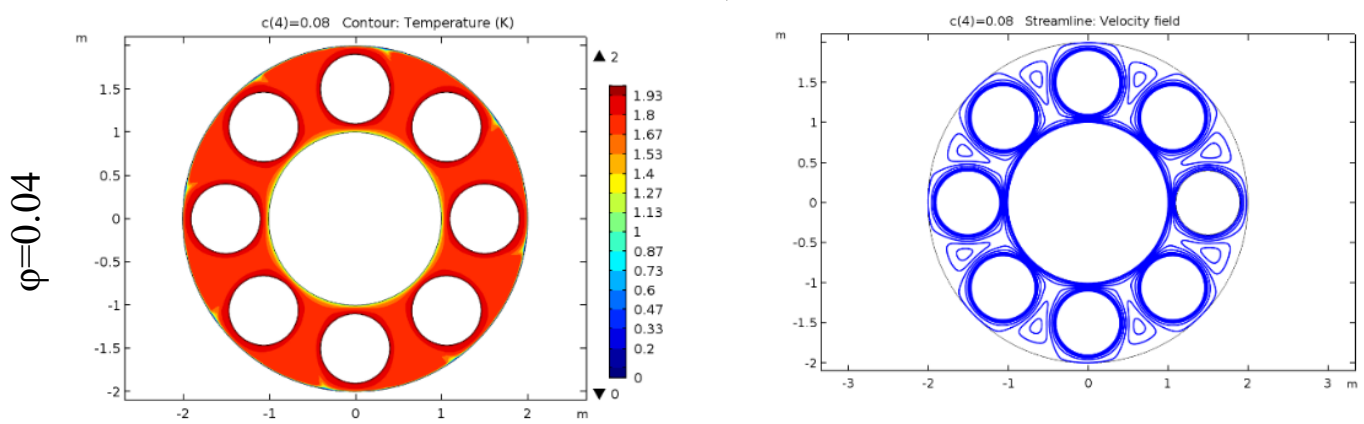

b)
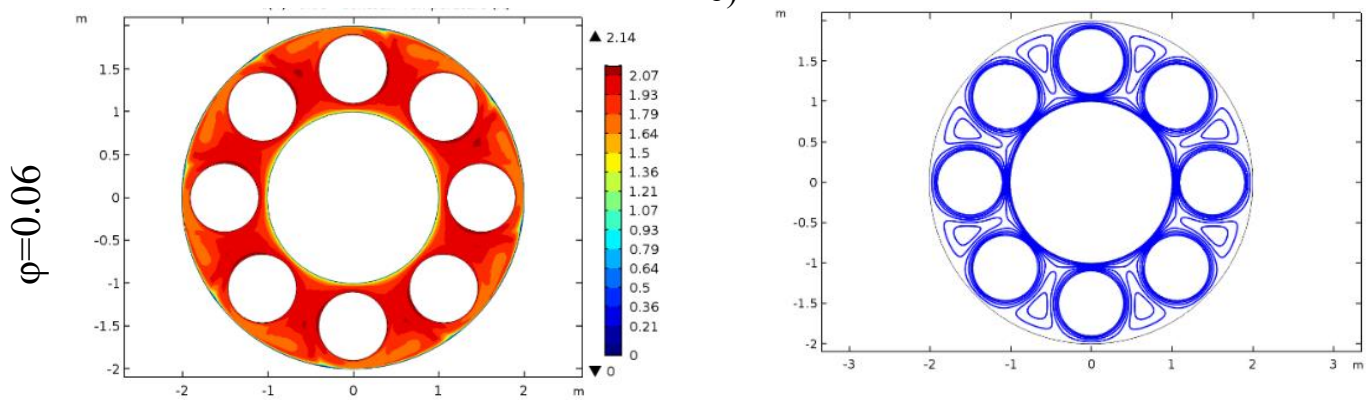

c)
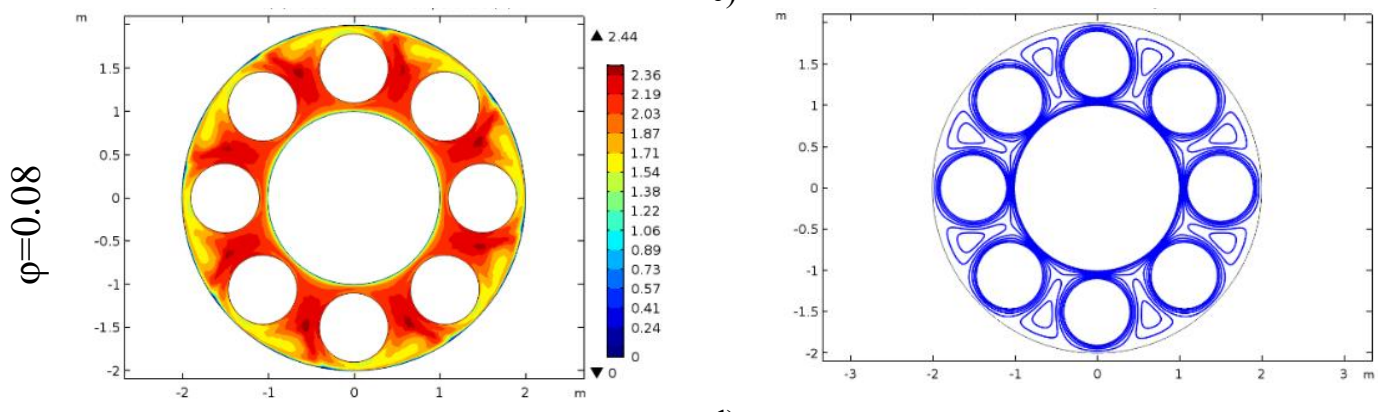

d)

Figure 14. Temperature contours and streamlines for spherical Alumina-PAO nano-lubricant for $\mathrm{Ra}=10000, \mathrm{Re}=25$ and different nanoparticles volume fractions, a) $0.02, \mathrm{~b}) 0.04, \mathrm{c}) 0.06, \mathrm{~d}) 0.08$ 


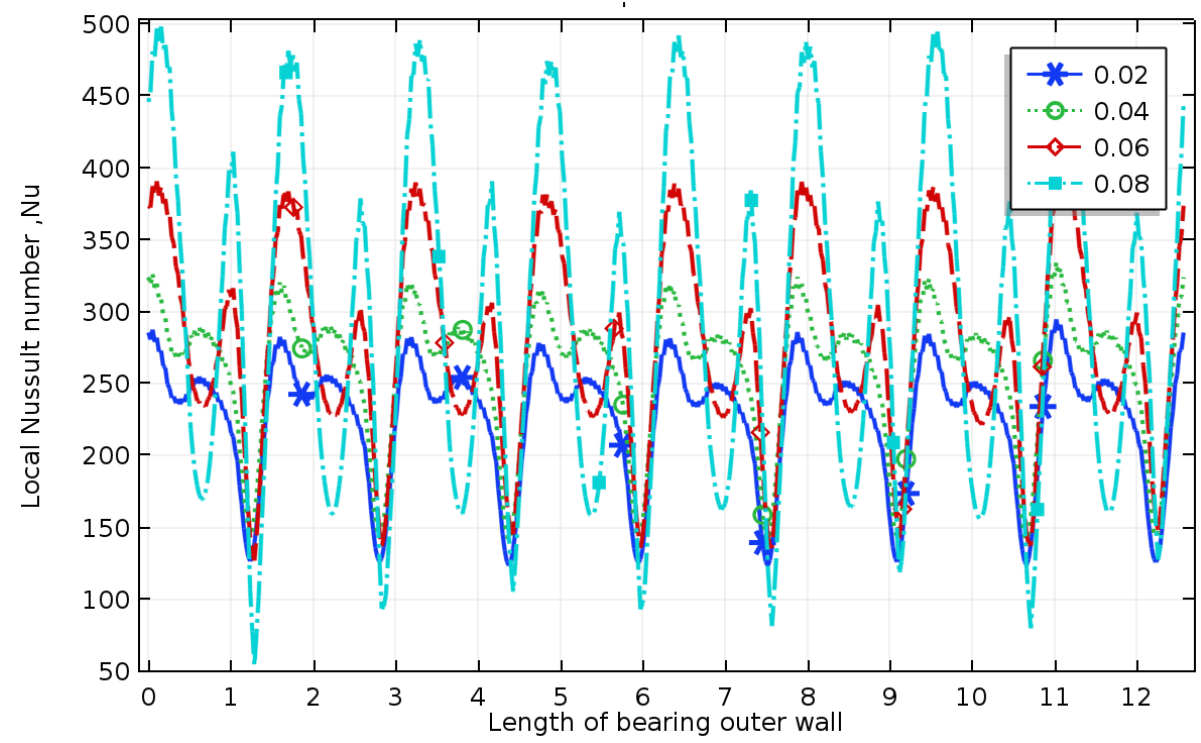

a)

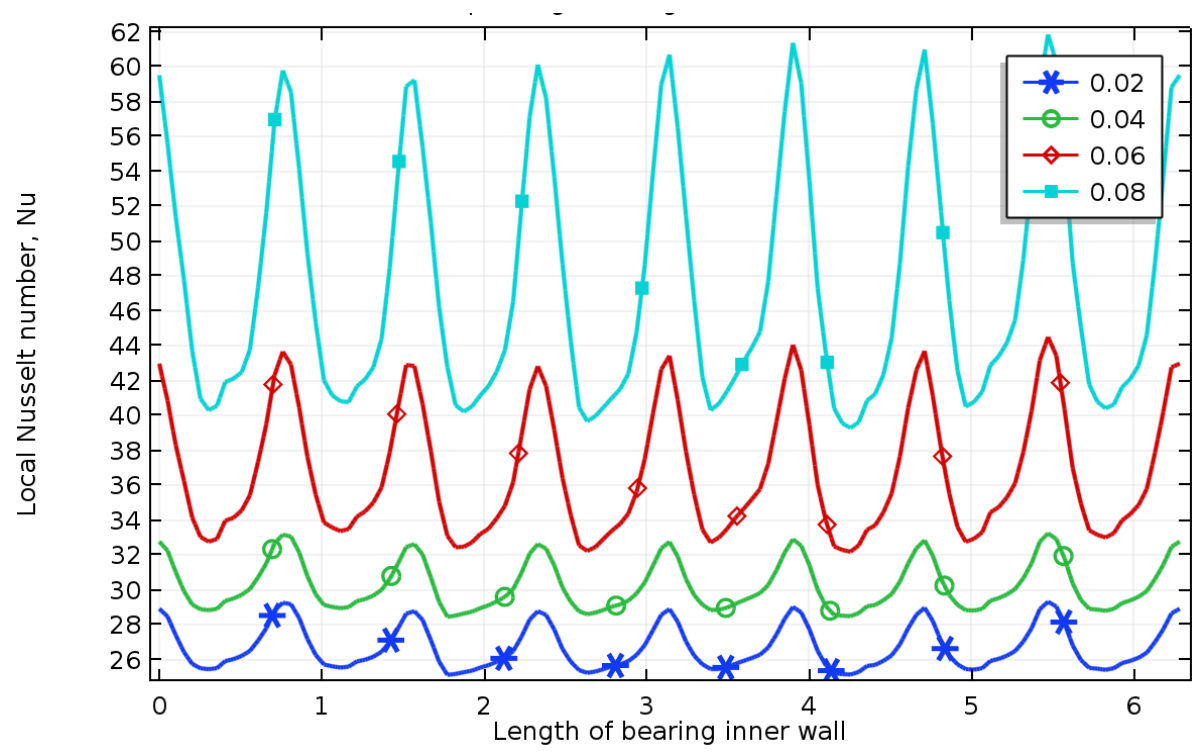

b)

Figure 15. a) Local Nusselt numbers of bearings outer and b) Local Nusselt numbers of bearings inner walls for spherical Alumina-PAO nano-lubricant when $\mathrm{Ra}=10000$ and $\mathrm{Re}=25$ and different nanoparticles volume fraction

\section{Average Nusselt Numbers}

To have a comparison between three described nano-lubricants, the average Nusselt numbers ( $\mathrm{Nu} 1$ and $\mathrm{Nu} 2$ ) are presented in Tables 4-9 to also show the effect of Rayleigh, Reynolds and nanoparticles volume fractions on the average Nusselt numbers. From these figures it can be visible that water-based nano-lubricant has the lowest Nusselt numbers, while the Nano-rod alumina-PAO has the maximum values for the Nusselt numbers and can be introduced as the most efficient nano-lubricant in this application. Table 4 and 5 reveal that in most cases increasing the Rayleigh number makes and increase in Nusselt number due to more natural convection heat transfer while Tables 6 and 7 exhibits that Reynolds increments have different treatments for water based and oil-based nano-lubricants which increase the $\mathrm{Nu}$ for the water based and decrease it for the oil-based nano-lubricants, averagely. As the last parameter 
Journal of Thermal Engineering, Research Article, Vol. 7, No. 2, Special Issue 13, pp. 134-161, February, 2021

study, Tables 8 and 9 show the effect of nanoparticles volume fraction on the Nusselt numbers. It is evident that greater values lead to higher thermal conductivity and consequently increase the Nusselt numbers.

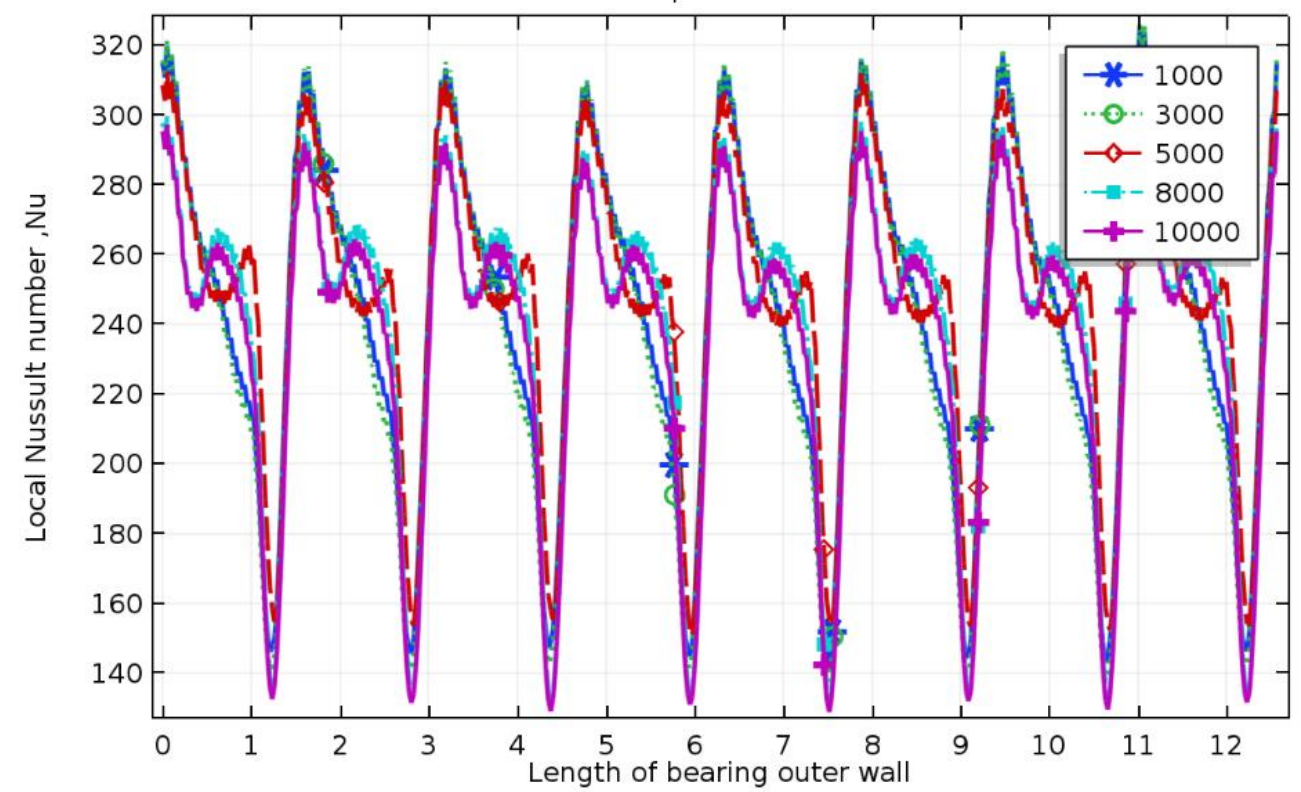

a)

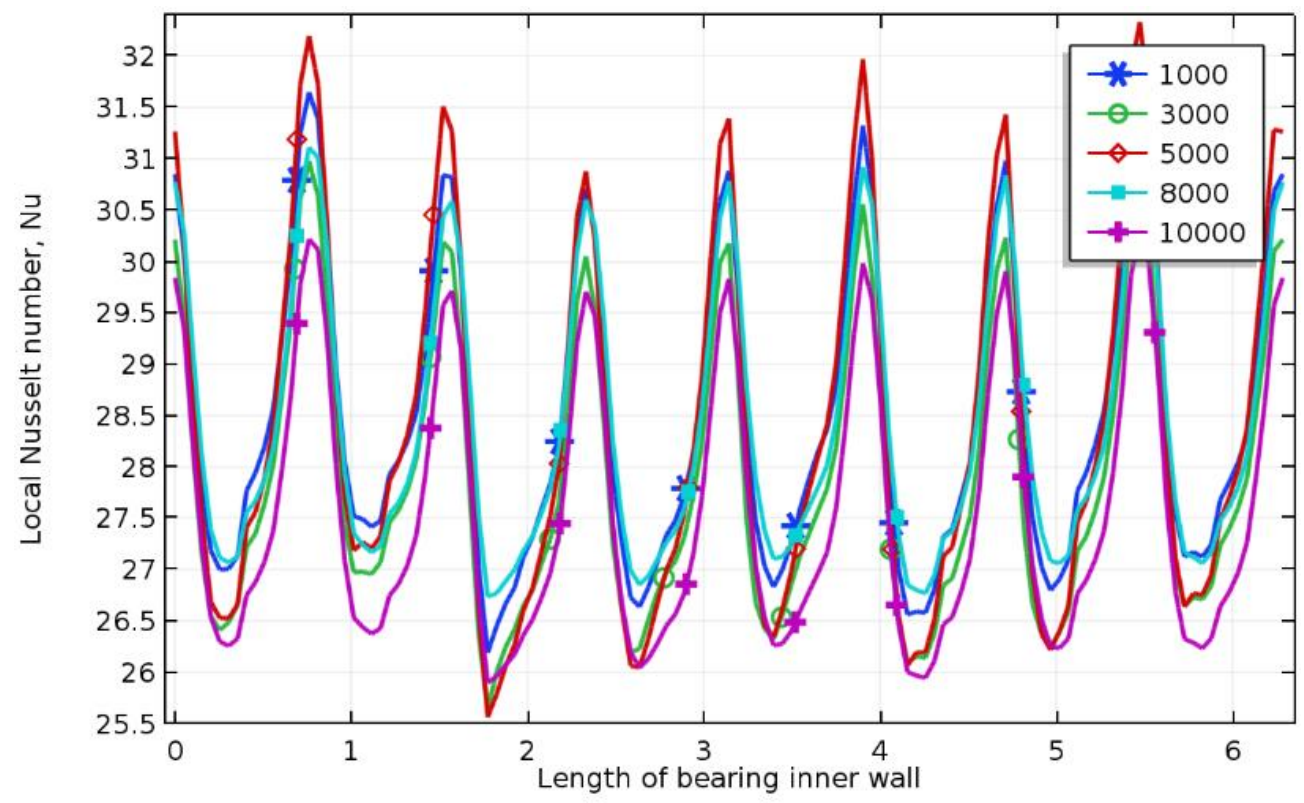

b)

Figure 16. a) Local Nusselt numbers of bearings outer and b) Local Nusselt numbers of bearings inner walls for Nano-rods Alumina-PAO nano-lubricant when $\mathrm{Re}=25$ and $\varphi=0.02$ and different Rayleigh numbers 


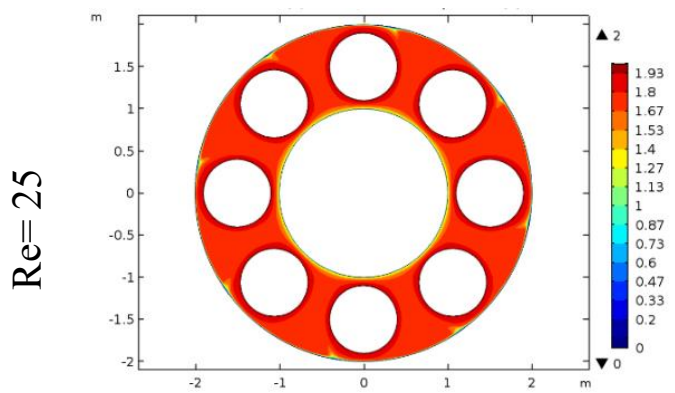

a)
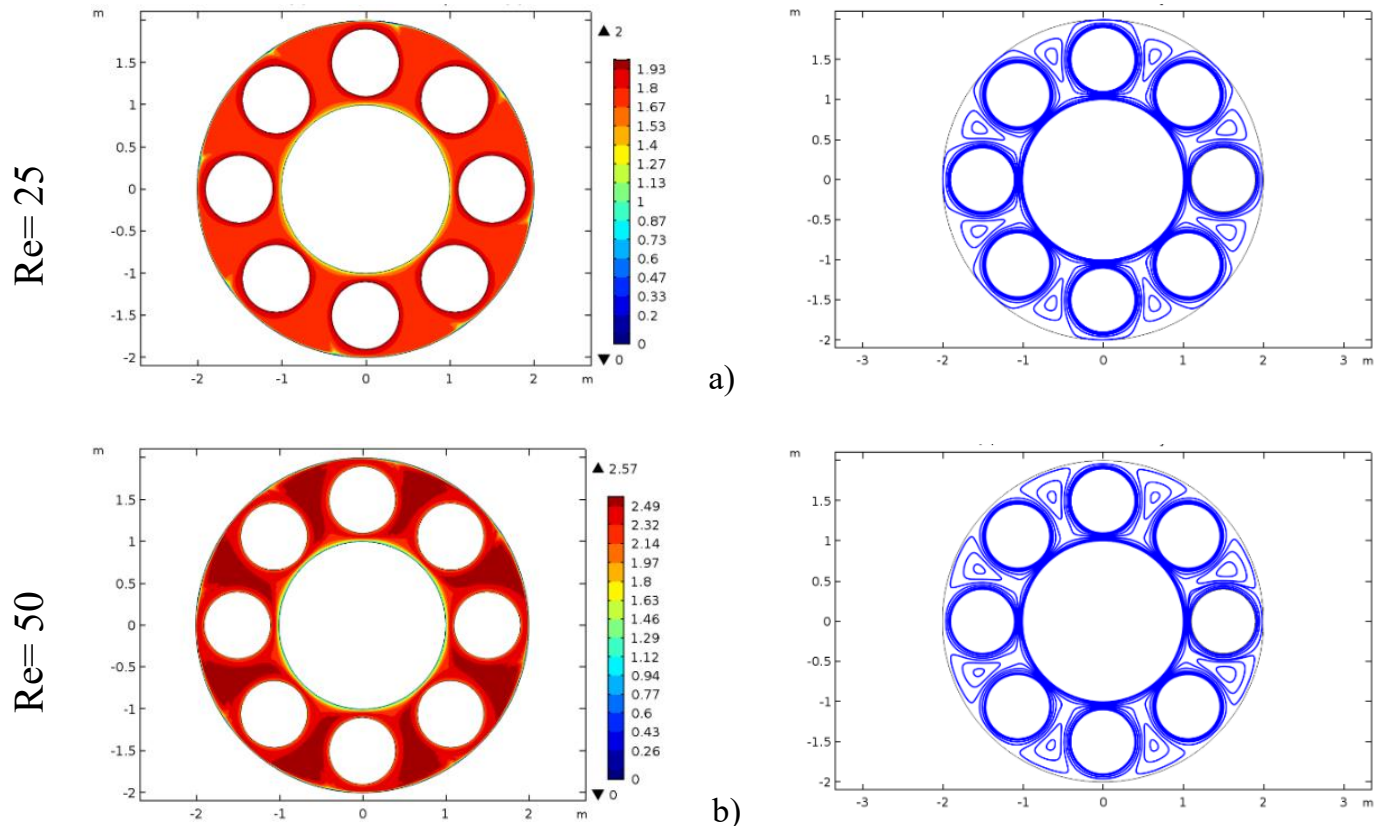

b)
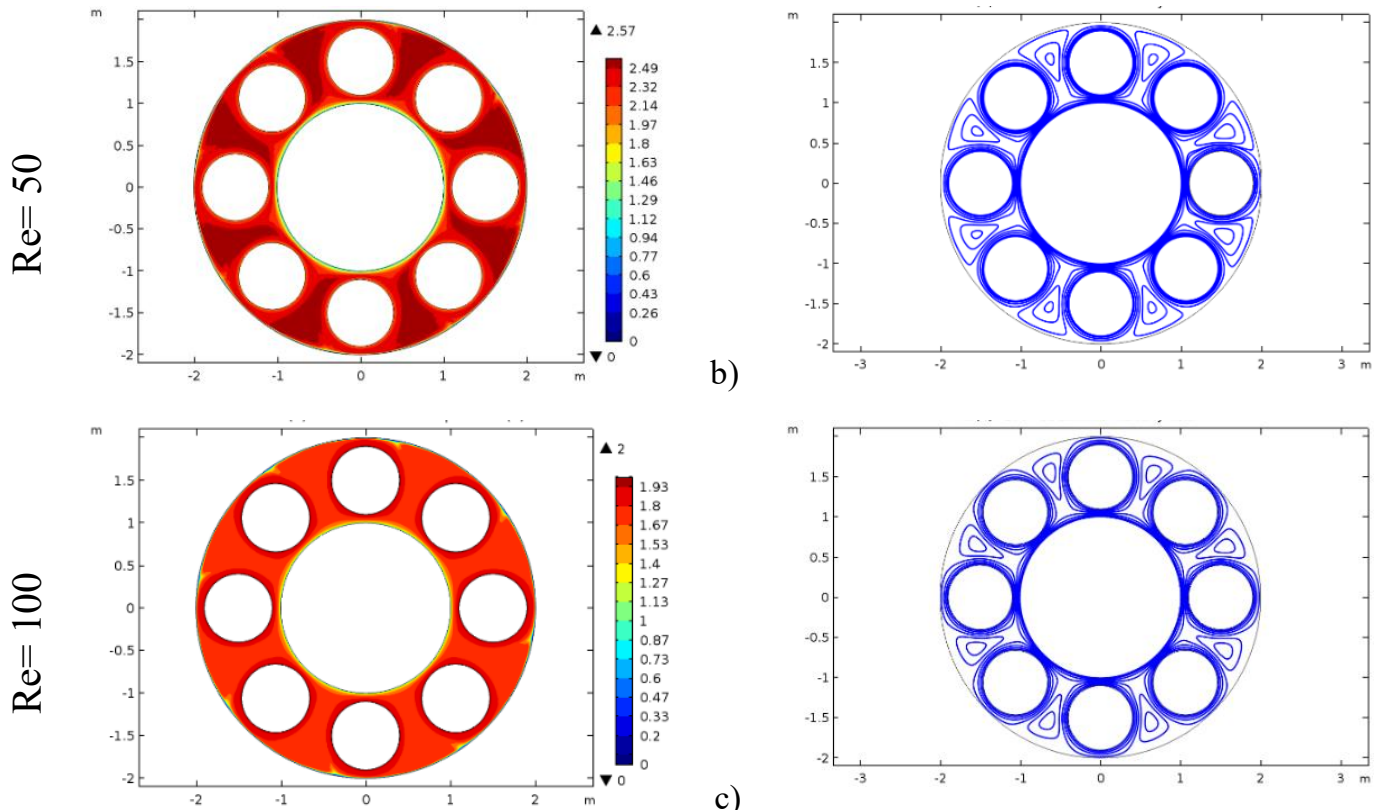

c)
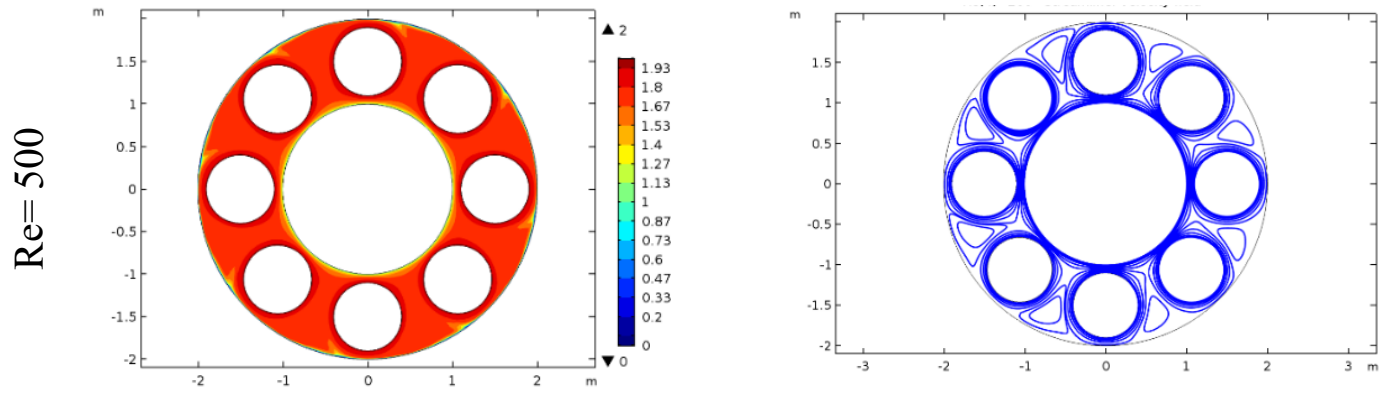

d)

Figure 17. Temperature contours and streamlines for nano-rods Alumina-PAO nano-lubricant for $\mathrm{Ra}=10000, \varphi=0.02$ and different Reynolds numbers a) 25, b) 50, c)100, d) 500 
Journal of Thermal Engineering, Research Article, Vol. 7, No. 2, Special Issue 13, pp. 134-161, February, 2021

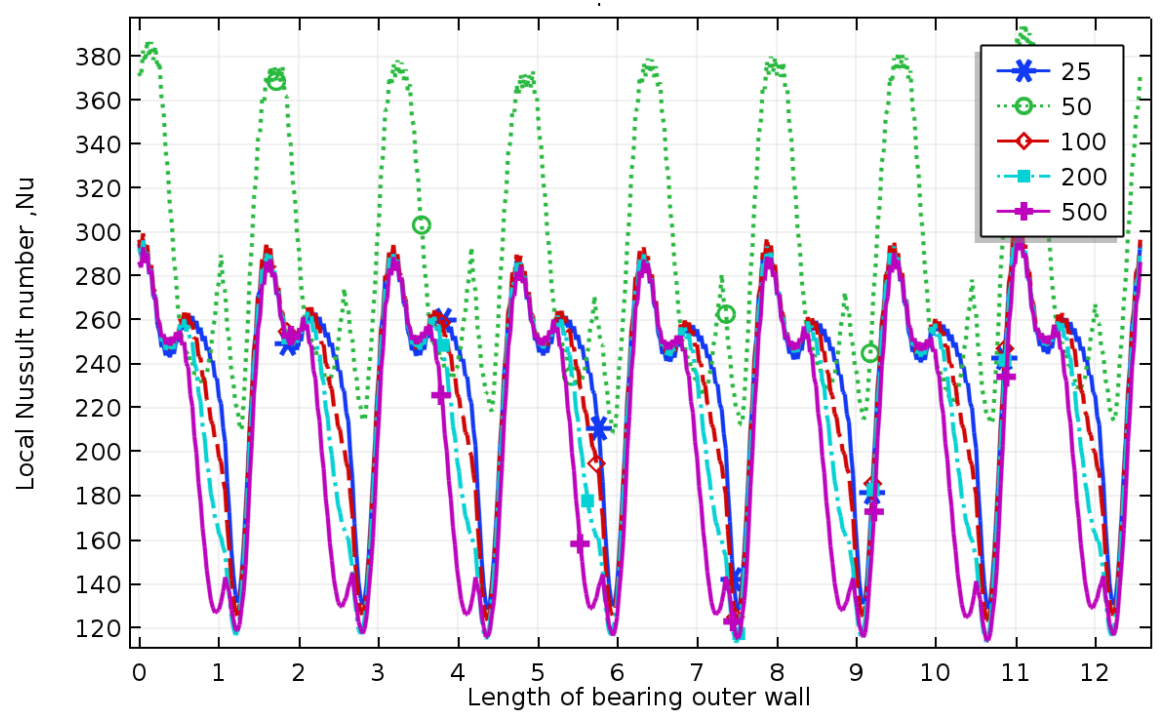

a)

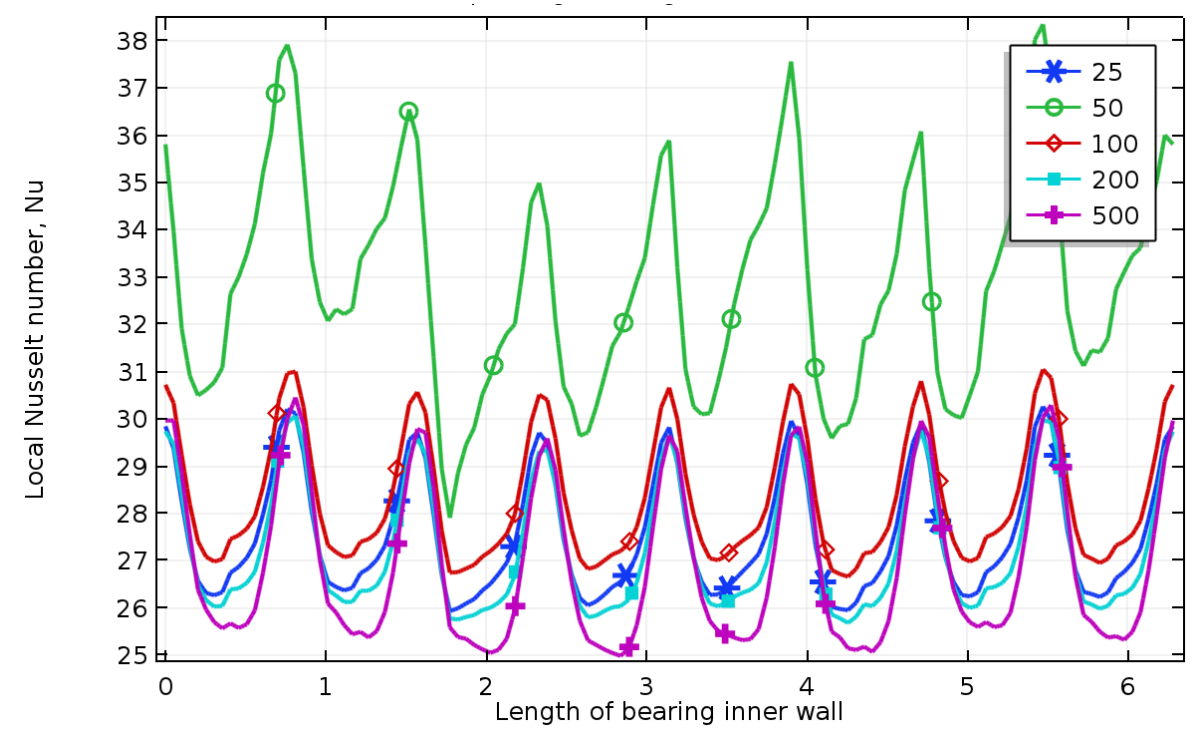

b)

Figure 18. a) Local Nusselt numbers of bearings outer and a) Local Nusselt numbers of bearings inner walls for nano-rods Alumina-PAO nano-lubricant when $\mathrm{Ra}=10000$ and $\varphi=0.02$ and different Reynolds numbers 


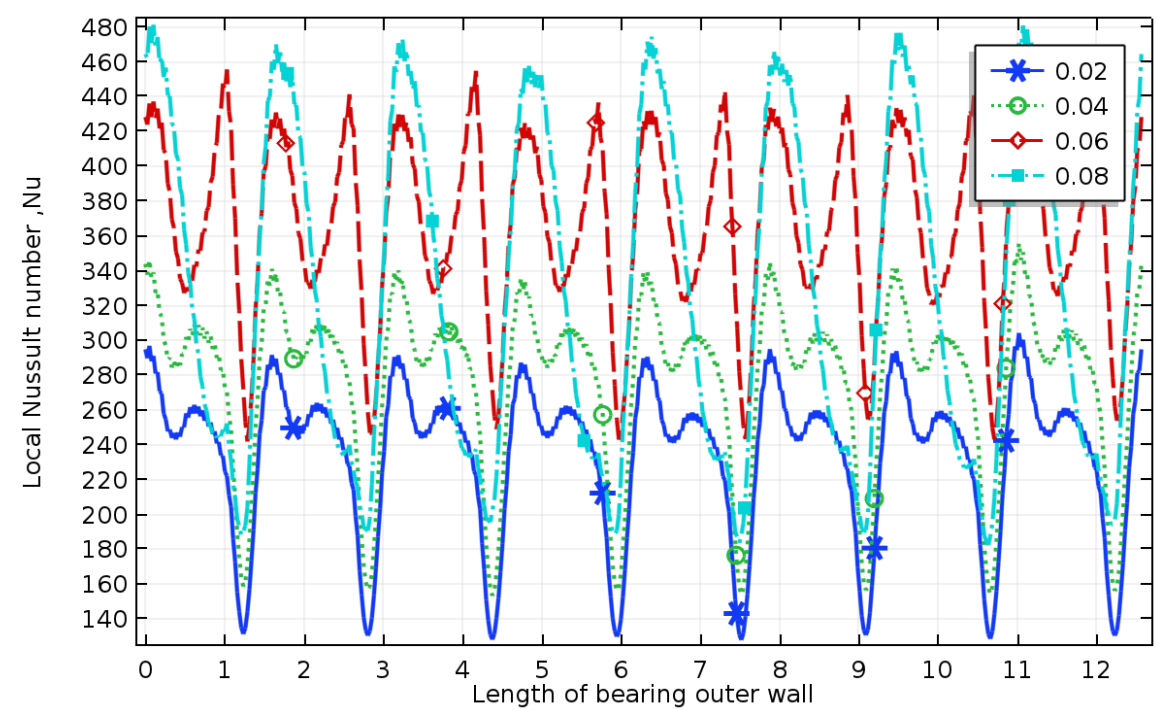

a)

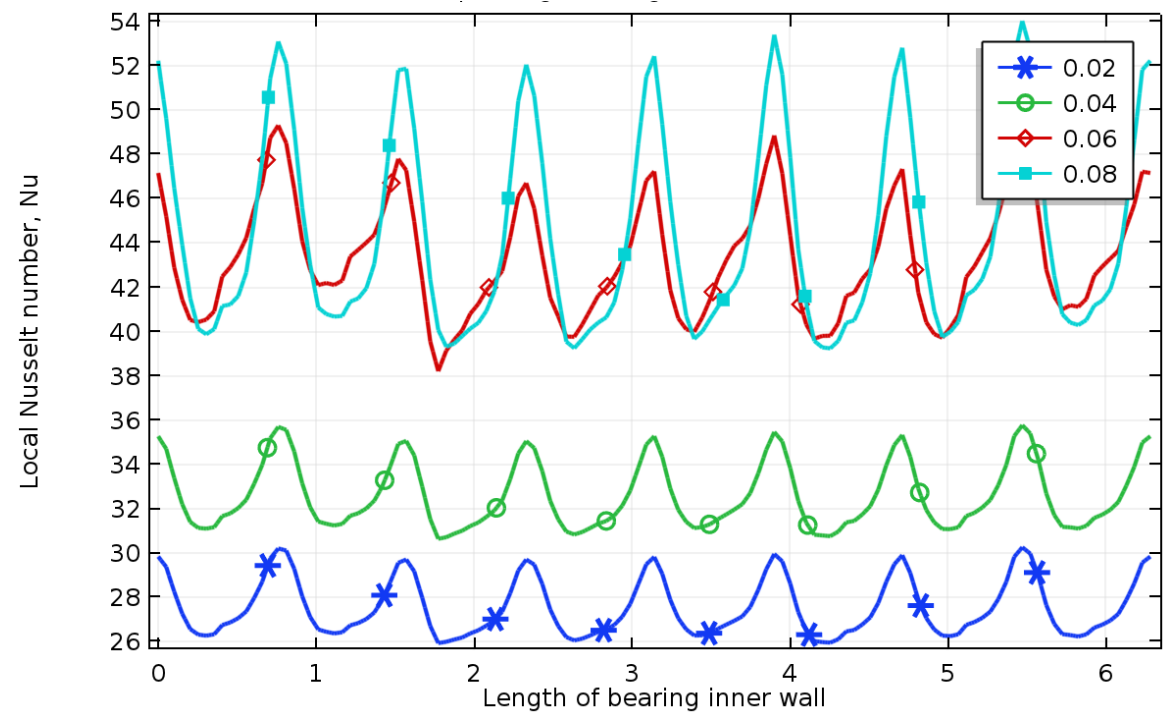

b)

Figure 19. a) Local Nusselt numbers of bearings outer and b) Local Nusselt numbers of bearings inner walls for nano-rods Alumina-PAO nano-lubricant when $\mathrm{Ra}=10000$ and $\mathrm{Re}=25$ and different nanoparticles volume fraction

\section{CONCLUSION}

In this paper, the mixed convection inside a mechanical ball bearing with the outer cold fixed wall and inner hot rotating wall and treated with nano-lubricants ( $\mathrm{SiO} 2$-water and Alumina-PAO) was studied numerically using COMSOL Multiphysics code built on a finite element method. The influence of Rayleigh number, Reynolds number, nanoparticles volume fraction, and shapes of nanoparticles on the heat transfer mechanism is investigated and it is found that Rayleigh number increament enhances the heat transfer process as well as the nanoparticles volume fraction, averagely, while the Reynolds increasing has different treatments. Also, the Nono-rod Alumina was found to show much greater heat transfer performance than the spherical alumina nano-particles. It was recommended that nano-rod Alumina-PAO has the best performance and maximum Nusselt numbers for the heat transfer in these applications. 
Journal of Thermal Engineering, Research Article, Vol. 7, No. 2, Special Issue 13, pp. 134-161, February, 2021

\section{ACKNOWLEDGEMENTS}

The authors gratefully acknowledge the general financial grant from the National Natural Science Foundation of China (No.51776165), China Postdoctoral Science Foundation (No. 2017M610638) and Shaanxi Provincial Postdoctoral Funds (2017BSHYDZZ16).

\section{NOMENCLATURE}

$\begin{array}{ll}\mathrm{Cp} & \text { specific heat at constant pressure, } \mathrm{kJ} / \mathrm{kg} \cdot \mathrm{K} \\ \mathrm{d} & \text { diameter } \\ \mathrm{g} & \text { gravitational acceleration, } \mathrm{m} / \mathrm{s}^{2} \\ \mathrm{~K} & \text { Boltzmann constant } \\ \mathrm{k} & \text { thermal conductivity, } \mathrm{W} / \mathrm{m} \cdot \mathrm{K} \\ \mathrm{Nu}_{\text {ave }} & \text { average Nusselt number of the hot inner cylinder } \\ \mathrm{Nu}_{\mathrm{loc}} & \text { local Nusselt number around hot inner cylinder } \\ \mathrm{P} & \text { dimensionless pressure } \\ \mathrm{p} & \text { Pressure, } \mathrm{Pa} \\ \mathrm{Pr} & \text { Prandtl number, } v \mathrm{f} / \mathrm{\alpha f} \\ \mathrm{Ra} & \text { Rayleigh number } \\ \mathrm{Re} & \text { Reynolds number } \\ \mathrm{T} & \text { Temperature, } \mathrm{K} \\ \mathrm{T}_{\mathrm{c}} & \text { temperature of the cold surface, } \mathrm{K} \\ \mathrm{T}_{\mathrm{h}} & \text { temperature of the hot surface, } \mathrm{K} \\ \mathrm{U} & \text { dimensionless velocity component in } \mathrm{x} \text { - direction } \\ \mathrm{u} & \text { velocity component in } \mathrm{x} \text { - direction, } \mathrm{m} / \mathrm{s} \\ \mathrm{V} & \text { dimensionless velocity component in } \mathrm{y}-\text { direction } \\ \mathrm{v} & \text { velocity component in } \mathrm{y}-\text { direction, } \mathrm{m} / \mathrm{s} \\ \mathrm{X} & \text { dimensionless coordinate in horizontal direction } \\ \mathrm{x} & \text { Cartesian coordinates in horizontal direction, } \mathrm{m} \\ \mathrm{Y} & \text { dimensionless coordinate in vertical direction } \\ \mathrm{y} & \text { Cartesian coordinate in vertical direction, } \mathrm{m}\end{array}$

$\begin{array}{ll}\text { Greek symbols } \\ \theta & \text { dimensionless temperature }\left(\mathrm{T}-\mathrm{T}_{\mathrm{c}} / \Delta \mathrm{T}\right) \\ \psi & \text { dimensional stream function }\left(\mathrm{m}^{2} / \mathrm{s}\right) \\ \Psi & \text { dimensionless stream function } \\ \mu & \text { dynamic viscosity }(\mathrm{kg} . \mathrm{s} / \mathrm{m}) \\ \Phi & \text { Internal domain } \\ \phi & \text { Nanoparticles concentration } \\ \lambda & \text { Penalty parameter } \\ \nu & \text { kinematic viscosity }(\mu / \rho)(\mathrm{Pa} . \mathrm{s}) \\ \Delta \mathrm{T} & \text { temperature difference } \\ \beta & \text { volumetric coefficient of thermal expansion, } \mathrm{K}^{-1} \\ \rho & \text { density, kg/m } \\ \omega & \text { angular velocity } \\ \text { Subscripts } & \\ \mathrm{c} & \text { Cold } \\ \mathrm{f} & \text { Fluid (pure) }\end{array}$


Journal of Thermal Engineering, Research Article, Vol. 7, No. 2, Special Issue 13, pp. 134-161, February, 2021

$\begin{array}{ll}\mathrm{p} & \text { Nanoparticle } \\ \text { eff } & \text { effective } \\ \mathrm{nf} & \text { Nanofluid } \\ \mathrm{r} & \text { relative } \\ \mathrm{o} & \text { outer } \\ \mathrm{i} & \text { inner }\end{array}$

\section{REFERENCES}

[1] Choi SU, Eastman JA. Enhancing thermal conductivity of fluids with nanoparticles. Argonne National Lab., IL (United States); 1995 Oct 1. DOI:10.1115/1.1532008.

[2] Mahian O, Kolsi L, Amani M, Estellé P, Ahmadi G, Kleinstreuer C, Marshall JS, Siavashi M, Taylor RA, Niazmand $\mathrm{H}$, Wongwises S. Recent advances in modeling and simulation of nanofluid flows-Part I: Fundamentals and theory. Physics reports. 2019 Feb 3;790:1-48. https://doi.org/10.1016/j.physrep.2018.11.004.

[3] Ghadimi A, Saidur R, Metselaar HS. A review of nanofluid stability properties and characterization in stationary conditions. International journal of heat and mass transfer. 2011 Aug 1;54(17-18):4051-68. https://doi.org/10.1016/j.ijheatmasstransfer.2011.04.014.

[4] Mahian O, Kianifar A, Heris SZ, Wen D, Sahin AZ, Wongwises S. Nanofluids effects on the evaporation rate in a solar still equipped with a heat exchanger. Nano Energy. 2017 Jun 1;36:134-55. https://doi.org/10.1016/j.nanoen.2017.04.025.

[5] Menni Y, Chamkha AJ, Lorenzini G, Kaid N, Ameur H, Bensafi M. Advances of nanofluids in solar collectorsa review of numerical studies advances of nanofluids in solar collectors - a review of numerical studies. Math Model Eng Probl. 2019;6(3):415-27. https://doi.org/10.18280/mmep.060313.

[6] Zhang Z, Cai J, Chen F, Li H, Zhang W, Qi W. Progress in enhancement of CO2 absorption by nanofluids: A mini review of mechanisms and current status. Renewable Energy. 2018 Apr 1;118:527-35. https://doi.org/10.1016/j.renene.2017.11.031.

[7] Taylor R, Coulombe S, Otanicar T, Phelan P, Gunawan A, Lv W, Rosengarten G, Prasher R, Tyagi H. Small particles, big impacts: a review of the diverse applications of nanofluids. Journal of applied physics. $2013 \mathrm{Jan}$ 7;113(1):1. https://doi.org/10.1063/1.4754271.

[8] Prasher R, Phelan PE, Bhattacharya P. Effect of aggregation kinetics on the thermal conductivity of nanoscale colloidal solutions (nanofluid). Nano letters. 2006 Jul 12;6(7):1529-34. https://doi.org/10.1021/nl060992s.

[9] Du M, Tang GH. Optical property of nanofluids with particle agglomeration. solar energy. 2015 Dec 1;122:86472. https://doi.org/10.1016/j.solener.2015.10.009.

[10] Song D, Wang Y, Jing D, Geng J. Investigation and prediction of optical properties of alumina nanofluids with different aggregation properties. International Journal of Heat and Mass Transfer. 2016 May 1;96:430-7. https://doi.org/10.1016/j.ijheatmasstransfer.2016.01.049.

[11] Sheikholeslami M. Numerical approach for MHD Al2O3-water nanofluid transportation inside a permeable medium using innovative computer method. Computer Methods in Applied Mechanics and Engineering. 2019 Feb 1;344:306-18. https://doi.org/10.1016/j.cma.2018.09.042.

[12] Haq RU, Soomro FA, Mekkaoui T, Al-Mdallal QM. MHD natural convection flow enclosure in a corrugated cavity filled with a porous medium. International Journal of Heat and Mass Transfer. 2018 Jun 1;121:1168-78. https://doi.org/10.1016/j.ijheatmasstransfer.2018.01.063.

[13] Ghadikolaei SS, Hosseinzadeh K, Ganji DD, Hatami M. Fe3O4-(CH2OH) 2 nanofluid analysis in a porous medium under MHD radiative boundary layer and dusty fluid. Journal of Molecular Liquids. 2018 May 15;258:172-85. https://doi.org/10.1016/j.molliq.2018.02.106.

[14] Hatami M, Song D, Jing D. Optimization of a circular-wavy cavity filled by nanofluid under the natural convection heat transfer condition. International Journal of Heat and Mass Transfer. 2016 Jul 1;98:758-67. https://doi.org/10.1016/j.ijheatmasstransfer.2016.03.063.

[15] Song D, Hatami M, Wang Y, Jing D, Yang Y. Prediction of hydrodynamic and optical properties of TiO2/water 
Journal of Thermal Engineering, Research Article, Vol. 7, No. 2, Special Issue 13, pp. 134-161, February, 2021

suspension considering particle size distribution. International Journal of Heat and Mass Transfer. 2016 Jan 1;92:864-76. https://doi.org/10.1016/j.ijheatmasstransfer.2015.08.101.

[16] Hatami M. Nanoparticles migration around the heated cylinder during the RSM optimization of a wavy-wall enclosure. Advanced Powder Technology. 2017 Mar 1;28(3):890-9. https://doi.org/10.1016/j.apt.2016.12.015.

[17] Tang W, Hatami M, Zhou J, Jing D. Natural convection heat transfer in a nanofluid-filled cavity with double sinusoidal wavy walls of various phase deviations. International Journal of Heat and Mass Transfer. 2017 Dec 1;115:430-40. https://doi.org/10.1016/j.ijheatmasstransfer.2017.07.057.

[18] Hatami M, Jing D. Optimization of wavy direct absorber solar collector (WDASC) using Al2O3-water nanofluid and RSM analysis. Applied Thermal Engineering. 2017 Jul 5;121:1040-50. https://doi.org/10.1016/j.applthermaleng.2017.04.137.

[19] Hatami M, Zhou J, Geng J, Song D, Jing D. Optimization of a lid-driven T-shaped porous cavity to improve the nanofluids mixed convection heat transfer. Journal of Molecular Liquids. 2017 Apr 1;231:620-31. https://doi.org/10.1016/j.molliq.2017.02.048.

[20] Zhou J, Hatami M, Song D, Jing D. Design of microchannel heat sink with wavy channel and its time-efficient optimization with combined RSM and FVM methods. International Journal of Heat and Mass Transfer. 2016 Dec 1;103:715-24. https://doi.org/10.1016/j.ijheatmasstransfer.2016.07.100.

[21] Afrand M, Najafabadi KN, Sina N, Safaei MR, Kherbeet AS, Wongwises S, Dahari M. Prediction of dynamic viscosity of a hybrid nano-lubricant by an optimal artificial neural network. International Communications in Heat and Mass Transfer. 2016 Aug 1;76:209-14. https://doi.org/10.1016/j.icheatmasstransfer.2016.05.023.

[22] Asadi A, Asadi M, Rezaniakolaei A, Rosendahl LA, Afrand M, Wongwises S. Heat transfer efficiency of Al2O3MWCNT/thermal oil hybrid nanofluid as a cooling fluid in thermal and energy management applications: An experimental and theoretical investigation. International Journal of Heat and Mass Transfer. 2018 Feb 1;117:474-86. https://doi.org/10.1016/j.ijheatmasstransfer.2017.10.036.

[23] Esfe MH, Esfandeh S. Investigation of rheological behavior of hybrid oil based nanolubricant-coolant applied in car engines and cooling equipments. Applied Thermal Engineering. 2018 Feb 25;131:1026-33. https://doi.org/10.1016/j.applthermaleng.2017.11.105.

[24] Ali MK, Xianjun H, Abdelkareem MA, Gulzar M, Elsheikh AH. Novel approach of the graphene nanolubricant for energy saving via anti-friction/wear in automobile engines. Tribology International. 2018 Aug 1;124:20929. https://doi.org/10.1016/j.triboint.2018.04.004.

[25] Ali MK, Fuming P, Younus HA, Abdelkareem MA, Essa FA, Elagouz A, Xianjun H. Fuel economy in gasoline engines using $\mathrm{Al} 2 \mathrm{O} 3 / \mathrm{TiO} 2$ nanomaterials as nanolubricant additives. Applied energy. 2018 Feb 1;211:461-78. https://doi.org/10.1016/j.apenergy.2017.11.013.

[26] Sharif MZ, Azmi WH, Redhwan AA, Mamat R, Yusof TM. Performance analysis of SiO2/PAG nanolubricant in automotive air conditioning system. international journal of refrigeration. 2017 Mar 1;75:204-16. https://doi.org/10.1016/j.ijrefrig.2017.01.004.

[27] Xia W, Zhao J, Wu H, Zhao X, Zhang X, Xu J, Jiao S, Wang X, Zhou C, Jiang Z. Effects of oil-in-water based nanolubricant containing TiO2 nanoparticles in hot rolling of 304 stainless steel. Journal of Materials Processing Technology. 2018 Dec 1;262:149-56. https://doi.org/10.1016/j.jmatprotec.2018.06.020.

[28] Wu H, Jia F, Zhao J, Huang S, Wang L, Jiao S, Huang H, Jiang Z. Effect of water-based nanolubricant containing nano-TiO2 on friction and wear behaviour of chrome steel at ambient and elevated temperatures. Wear. 2019 Apr 30;426:792-804. https://doi.org/10.1016/j.wear.2018.11.023.

[29] Ali FH, Hamzah HK, Abdulkadhim A. Numerical study of mixed convection nanofluid in an annulus enclosure between outer rotating cylinder and inner corrugation cylinder. Heat Transfer-Asian Research. 2019 Jan;48(1):343-60. https://doi.org/10.1002/htj.21387.

[30] Saleh H, Alsabery AI, Hashim I. Natural convection in polygonal enclosures with inner circular cylinder. Advances in Mechanical Engineering. 2015 Dec 17;7(12):1687814015622899. https://doi.org/10.1177\%2F1687814015622899.

[31] Bao Y, Sun J, Kong L. Effects of nano-SiO2 as water-based lubricant additive on surface qualities of strips after hot rolling. Tribology International. 2017 Oct 1;114:257-63. https://doi.org/10.1016/j.triboint.2017.04.026. 
Journal of Thermal Engineering, Research Article, Vol. 7, No. 2, Special Issue 13, pp. 134-161, February, 2021

[32] Xie H, Dang S, Jiang B, Xiang L, Zhou S, Sheng H, Yang T, Pan F. Tribological performances of SiO2/graphene combinations as water-based lubricant additives for magnesium alloy rolling. Applied Surface Science. 2019 May 1;475:847-56. https://doi.org/10.1016/j.apsusc.2019.01.062.

[33] Ajeel RK, Salim WI, Hasnan K. Influences of geometrical parameters on the heat transfer characteristics through symmetry trapezoidal-corrugated channel using $\mathrm{SiO} 2$-water nanofluid. International Communications in Heat and Mass Transfer. 2019 Feb 1;101:1-9. https://doi.org/10.1016/j.icheatmasstransfer.2018.12.016.

[34] Vajjha RS, Das DK, Kulkarni DP. Development of new correlations for convective heat transfer and friction factor in turbulent regime for nanofluids. International journal of heat and mass transfer. 2010 Oct 1;53(2122):4607-18. https://doi.org/10.1016/j.ijheatmasstransfer.2010.06.032.

[35] Jumpholkul C, Mahian O, Kasaeian A, Dalkilic AS, Wongwises S. An experimental study to determine the maximum efficiency index in turbulent flow of $\mathrm{SiO} 2 /$ water nanofluids. International Journal of Heat and Mass Transfer. 2017 Sep 1;112:1113-21. https://doi.org/10.1016/j.ijheatmasstransfer.2017.05.007.

[36] Zolper T, Li Z, Chen C, Jungk M, Marks T, Chung YW, Wang Q. Lubrication properties of polyalphaolefin and polysiloxane lubricants: molecular structure-tribology relationships. Tribology letters. 2012 Dec 1;48(3):35565. http://dx.doi.org/10.1007/s11249-013-0103-4.

[37] Hajmohammadi MR. Assessment of a lubricant based nanofluid application in a rotary system. Energy Conversion and Management. 2017 Aug 15;146:78-86. https://doi.org/10.1016/j.enconman.2017.04.071.

[38] Ghajar AJ, Tang WC, Beam JE. Methodology for comparison of hydraulic and thermal performance of alternative heat transfer fluids in complex systems. Heat transfer engineering. 1995 Jan 1;16(1):60-72. https://doi.org/10.1080/01457639508939846.

[39] Yu L, Liu D, Botz F. Laminar convective heat transfer of alumina-polyalphaolefin nanofluids containing spherical and non-spherical nanoparticles. Experimental thermal and fluid science. 2012 Feb 1;37:72-83. https://doi.org/10.1016/j.expthermflusci.2011.10.005.

[40] O.K.C.R.L. Hamilton, IEC Fundamentals, 2, 1962.

[41] Vu T, Tran TN, Xu J. Single-phase flow and heat transfer characteristics of ethanol/polyalphaolefin nanoemulsion fluids in circular minichannels. International Journal of Heat and Mass Transfer. 2017 Oct 1;113:324-31. https://doi.org/10.1016/j.ijheatmasstransfer.2017.05.088.

[42] Sajid MU, Ali HM, Sufyan A, Rashid D, Zahid SU, Rehman WU. Experimental investigation of TiO 2-water nanofluid flow and heat transfer inside wavy mini-channel heat sinks. Journal of Thermal Analysis and Calorimetry. 2019 Aug 30;137(4):1279-94. https://doi.org/10.1007/s10973-019-08043-9.

[43] Javed S, Ali HM, Babar H, Khan MS, Janjua MM, Bashir MA. Internal convective heat transfer of nanofluids in different flow regimes: A comprehensive review. Physica A: Statistical Mechanics and its Applications. 2020 Jan 15;538:122783. https://doi.org/10.1016/j.physa.2019.122783.

[44] Abbas N, Awan MB, Amer M, Ammar SM, Sajjad U, Ali HM, Zahra N, Hussain M, Badshah MA, Jafry AT. Applications of nanofluids in photovoltaic thermal systems: a review of recent advances. Physica A: Statistical Mechanics and its Applications. 2019 Aug 28:122513. https://doi.org/10.1016/j.physa.2019.122513.

[45] Hussein AK, Kolsi L, Almeshaal MA, Li D, Ali HM, Ahmed IS. Mixed convection in a cubical cavity with active lateral walls and filled with hybrid graphene-platinum nanofluid. Journal of Thermal Science and Engineering Applications. 2019 Aug 1;11(4). https://doi.org/10.1115/1.4043758.

[46] Wahab A, Hassan A, Qasim MA, Ali HM, Babar H, Sajid MU. Solar energy systems-Potential of nanofluids. Journal of Molecular Liquids. 2019 Jun 3:111049. https://doi.org/10.1016/j.molliq.2019.111049.

[47] Shah TR, Ali HM. Applications of hybrid nanofluids in solar energy, practical limitations and challenges: a critical review. Solar Energy. 2019 May 1;183:173-203. https://doi.org/10.1016/j.solener.2019.03.012.

[48] Sajid MU, Ali HM. Recent advances in application of nanofluids in heat transfer devices: a critical review. Renewable and Sustainable Energy Reviews. 2019 Apr 1;103:556-92. https://doi.org/10.1016/j.rser.2018.12.057.

[49] Shashikumar NS, Gireesha BJ, Mahanthesh B, Prasannakumara BC, Chamkha AJ. Entropy generation analysis of magneto-nanoliquids embedded with aluminium and titanium alloy nanoparticles in microchannel with partial slips and convective conditions. International Journal of Numerical Methods for Heat \& Fluid Flow. 
Journal of Thermal Engineering, Research Article, Vol. 7, No. 2, Special Issue 13, pp. 134-161, February, 2021

2019 Oct 7. https://doi.org/10.1108/HFF-06-2018-0301.

[50] Selimefendigil F, Öztop HF, Chamkha AJ. Mixed Convection of Pulsating Ferrofluid Flow Over a BackwardFacing Step. Iranian Journal of Science and Technology, Transactions of Mechanical Engineering. 2019 Dec 1;43(4):593-612. https://doi.org/10.1007/s40997-018-0238-x.

[51] Kumar B, Seth GS, Nandkeolyar R, Chamkha AJ. Outlining the impact of induced magnetic field and thermal radiation on magneto-convection flow of dissipative fluid. International Journal of Thermal Sciences. 2019 Dec 1;146:106101. https://doi.org/10.1016/j.ijthermalsci.2019.106101.

[52] Alsabery AI, Saleh H, Ghalambaz M, Chamkha AJ, Hashim I. Fluid-structure interaction analysis of transient convection heat transfer in a cavity containing inner solid cylinder and flexible right wall. International Journal of Numerical Methods for Heat \& Fluid Flow. 2019 Jul 11. https://doi.org/10.1108/HFF-10-2018-0593.

[53] Tayebi T, Chamkha AJ, Djezzar M. Natural convection of CNT-water nanofluid in an annular space between confocal elliptic cylinders with constant heat flux on inner wall. Scientia Iranica. Transaction B, Mechanical Engineering. 2019 Oct 1;26(5):2770-83.

[54] Alsabery AI, Selimefendigil F, Hashim I, Chamkha AJ, Ghalambaz M. Fluid-structure interaction analysis of entropy generation and mixed convection inside a cavity with flexible right wall and heated rotating cylinder. International Journal of Heat and Mass Transfer. 2019 Sep 1;140:331-45. https://doi.org/10.1016/j.ijheatmasstransfer.2019.06.003.

[55] Dogonchi AS, Armaghani T, Chamkha AJ, Ganji DD. Natural convection analysis in a cavity with an inclined elliptical heater subject to shape factor of nanoparticles and magnetic field. Arabian Journal for Science and Engineering. 2019 Sep 1;44(9):7919-31. https://doi.org/10.1007/s13369-019-03956-x.

[56] Ghalambaz M, Chamkha AJ, Wen D. Natural convective flow and heat transfer of nano-encapsulated phase change materials (NEPCMs) in a cavity. International Journal of Heat and Mass Transfer. 2019 Aug 1;138:73849. https://doi.org/10.1016/j.ijheatmasstransfer.2019.04.037.

[57] Sadeghi HM, Babayan M, Chamkha A. Investigation of using multi-layer PCMs in the tubular heat exchanger with periodic heat transfer boundary condition. International Journal of Heat and Mass Transfer. 2020 Feb 1;147:118970. https://doi.org/10.1016/j.ijheatmasstransfer.2019.118970.

[58] Ghalambaz M, Tahmasebi A, Chamkha AJ, Wen D. Conjugate local thermal non-equilibrium heat transfer in a cavity filled with a porous medium: Analysis of the element location. International Journal of Heat and Mass Transfer. 2019 Aug 1;138:941-60. https://doi.org/10.1016/j.ijheatmasstransfer.2019.03.073.

[59] Hoseinzadeh S, Moafi A, Shirkhani A, Chamkha AJ. Numerical validation heat transfer of rectangular crosssection porous fins. Journal of Thermophysics and Heat Transfer. 2019 Jul;33(3):698-704. https://doi.org/10.2514/1.T5583.

[60] Chamkha AJ, Sazegar S, Jamesahar E, Ghalambaz M. Thermal non-equilibrium heat transfer modeling of hybrid nanofluids in a structure composed of the layers of solid and porous media and free nanofluids. Energies. 2019 Jan;12(3):541. https://doi.org/10.3390/en12030541.

[61] Ayoubloo KA, Ghalambaz M, Armaghani T, Noghrehabadi A, Chamkha AJ. Pseudoplastic natural convection flow and heat transfer in a cylindrical vertical cavity partially filled with a porous layer. International Journal of Numerical Methods for Heat \& Fluid Flow. 2019 Sep 30. https://doi.org/10.1108/HFF-06-2019-0464.

[62] Ghalambaz M, Mehryan SA, Ismael MA, Chamkha A, Wen D. Fluid-structure interaction of free convection in a square cavity divided by a flexible membrane and subjected to sinusoidal temperature heating. International Journal of Numerical Methods for Heat \& Fluid Flow. 2019 Jun 6. https://doi.org/10.1108/HFF-12-2018-0826.

[63] Alsabery AI, Ismael MA, Chamkha AJ, Hashim I. Effect of nonhomogeneous nanofluid model on transient natural convection in a non-Darcy porous cavity containing an inner solid body. International Communications in Heat and Mass Transfer. 2020 Jan 1;110:104442. https://doi.org/10.1016/j.icheatmasstransfer.2019.104442.

[64] Ishak MS, Alsabery AI, Chamkha A, Hashim I. Effect of finite wall thickness on entropy generation and natural convection in a nanofluid-filled partially heated square cavity. International Journal of Numerical Methods for Heat \& Fluid Flow. 2019 Nov 1. https://doi.org/10.1108/HFF-06-2019-0505.

[65] Tayebi T, Chamkha AJ. Entropy generation analysis during MHD natural convection flow of hybrid nanofluid in a square cavity containing a corrugated conducting block. International Journal of Numerical Methods for 
Journal of Thermal Engineering, Research Article, Vol. 7, No. 2, Special Issue 13, pp. 134-161, February, 2021

Heat \& Fluid Flow. 2019 Sep 12. https://doi.org/10.1108/HFF-04-2019-0350.

[66] Alsabery AI, Gedik E, Chamkha AJ, Hashim I. Impacts of heated rotating inner cylinder and two-phase nanofluid model on entropy generation and mixed convection in a square cavity. Heat and Mass Transfer. 2020 Jan;56(1):321-38. https://doi.org/10.1007/s00231-019-02698-8.

[67] Alsabery AI, Armaghani T, Chamkha AJ, Hashim I. Two-phase nanofluid model and magnetic field effects on mixed convection in a lid-driven cavity containing heated triangular wall. Alexandria Engineering Journal. 2020 Feb 1;59(1):129-48. https://doi.org/10.1016/j.aej.2019.12.017.

[68] Hoseinzadeh S, Heyns PS, Chamkha AJ, Shirkhani A. Thermal analysis of porous fins enclosure with the comparison of analytical and numerical methods. Journal of Thermal Analysis and Calorimetry. 2019 Oct 1;138(1):727-35. https://doi.org/10.1007/s10973-019-08203-x.

[69] Alsabery AI, Mohebbi R, Chamkha AJ, Hashim I. Impacts of magnetic field and non-homogeneous nanofluid model on convective heat transfer and entropy generation in a cavity with heated trapezoidal body. Journal of Thermal Analysis and Calorimetry. 2019 Oct 1;138(2):1371-94. https://doi.org/10.1007/s10973-019-08249-x.

[70] Mehryan SA, Izadi M, Namazian Z, Chamkha AJ. Natural convection of multi-walled carbon nanotube-Fe $3 \mathrm{O}$ 4/water magnetic hybrid nanofluid flowing in porous medium considering the impacts of magnetic fielddependent viscosity. Journal of Thermal Analysis and Calorimetry. 2019 Oct 1;138(2):1541-55. https://doi.org/10.1007/s10973-019-08164-1.

[71] Ghalambaz M, Mehryan SA, Izadpanahi E, Chamkha AJ, Wen D. MHD natural convection of Cu-Al 2 O 3 water hybrid nanofluids in a cavity equally divided into two parts by a vertical flexible partition membrane. Journal of Thermal Analysis and Calorimetry. 2019 Oct 1;138(2):1723-43. https://doi.org/10.1007/s10973-01908258-w.

[72] Rejvani M, Saedodin S, Vahedi SM, Wongwises S, Chamkha AJ. Experimental investigation of hybrid nanolubricant for rheological and thermal engineering applications. Journal of Thermal Analysis and Calorimetry. 2019 Oct 1;138(2):1823-39. https://doi.org/10.1007/s10973-019-08225-5.

[73] Mehryan SA, Izadpanahi E, Ghalambaz M, Chamkha AJ. Mixed convection flow caused by an oscillating cylinder in a square cavity filled with $\mathrm{Cu}-\mathrm{Al} 2 \mathrm{O}$ 3/water hybrid nanofluid. Journal of Thermal Analysis and Calorimetry. 2019 Aug 15;137(3):965-82. https://doi.org/10.1007/s10973-019-08012-2.

[74] Alsabery AI, Mohebbi R, Chamkha AJ, Hashim I. Effect of local thermal non-equilibrium model on natural convection in a nanofluid-filled wavy-walled porous cavity containing inner solid cylinder. Chemical Engineering Science. 2019 Jun 29;201:247-63. https://doi.org/10.1016/j.ces.2019.03.006.

[75] Ghalambaz M, Doostani A, Izadpanahi E, Chamkha AJ. Conjugate natural convection flow of $\mathrm{Ag}-\mathrm{MgO} / \mathrm{water}$ hybrid nanofluid in a square cavity. Journal of Thermal Analysis and Calorimetry. 2020 Feb 1;139(3):2321-36. https://doi.org/10.1007/s10973-019-08617-7.

[76] Dogonchi AS, Tayebi T, Chamkha AJ, Ganji DD. Natural convection analysis in a square enclosure with a wavy circular heater under magnetic field and nanoparticles. Journal of Thermal Analysis and Calorimetry. 2020 Jan;139(1):661-71. https://doi.org/10.1007/s10973-019-08408-0.

[77] Javadi MA, Hoseinzadeh S, Ghasemiasl R, Heyns PS, Chamkha AJ. Sensitivity analysis of combined cycle parameters on exergy, economic, and environmental of a power plant. Journal of Thermal Analysis and Calorimetry. 2020 Jan;139(1):519-25. https://doi.org/10.1007/s10973-019-08399-y.

[78] Hashemi-Tilehnoee M, Dogonchi AS, Seyyedi SM, Chamkha AJ, Ganji DD. Magnetohydrodynamic natural convection and entropy generation analyses inside a nanofluid-filled incinerator-shaped porous cavity with wavy heater block. Journal of Thermal Analysis and Calorimetry. 2020 Jan 11:1-3. https://doi.org/10.1007/s10973-019-09220-6.

[79] Menni Y, Chamkha AJ, Azzi A. NANOFLUID TRANSPORT IN POROUS MEDIA: A REVIEW. Special Topics \& Reviews in Porous Media: An International Journal. 2019;10(1).

[80] Menni Y, Chamkha AJ, Azzi A. Nanofluid flow in complex geometries - a review. Journal of Nanofluids. 2019 May 1;8(5):893-916. https://doi.org/10.1166/jon.2019.1663.

[81] Menni Y, Chamkha AJ, Lorenzini G, Kaid N, Ameur H, Bensafi M. Advances of nanofluids in solar collectorsa review of numerical studies advances of nanofluids in solar collectors - a review of numerical studies. Math 
Model Eng Probl. 2019;6(3):415-27. https://doi.org/10.18280/mmep.060313.

[82] Menni Y, Chamkha A, Zidani C, Benyoucef B. Heat and nanofluid transfer through baffled channels in different outlet models. Math Model Eng Probl. 2019;6(1):21-8.

[83] Menni Y, Chamkha AJ, Zidani C, Benyoucef B. Numerical analysis of heat and nanofluid mass transfer in a channel with detached and attached baffle plates Numerical analysis of heat and nanofluid mass transfer in a channel with detached and attached baffle plates. https://doi.org/10.18280/mmep.060107.

[84] Menni Y, Chamkha AJ, Massarotti N, Ameur H, Kaid N, Bensafi M. Hydrodynamic and thermal analysis of water, ethylene glycol and water-ethylene glycol as base fluids dispersed by aluminum oxide nano-sized solid particles. International Journal of Numerical Methods for Heat \& Fluid Flow. 2020 Jan 2. https://doi.org/10.1108/HFF-10-2019-0739.

[85] Ismail T. A new analytical investigation of natural convection of non-Newtonian nanofluids flow between two vertical flat plates by the generalized decomposition method (GDM). Journal of Thermal Engineering. 2018 Oct 1;4(6):2496-508. https://doi.org/10.18186/thermal.465731.

[86] Belhadj A. Numerical investigation of forced convection of nanofluid in microchannels heat sinks. Journal of Thermal Engineering. 2018 Jul 1;4(5):2263-73. https://doi.org/10.18186/thermal.438480.

[87] Ravisankar R, Venkatachalapathy VS, Alagumurthi N. Application of nanotechnology to improve the performance of tractor radiator using cu-water nanofluid. Journal of Thermal Engineering. 2018 Jun 1;4(4):2188-200. https://doi.org/10.18186/journal-of-thermal-engineering.434036.

[88] Abbassi MA, Djebali R, Guedri K. Effects of heater dimensions on nanofluid natural convection in a heated incinerator shaped cavity containing a heated block. Journal of Thermal Engineering. 2018 Apr 1;4(3). https://doi.org/10.18186/journal-of-thermal-engineering.411434. 